\title{
Seismic characterization of a rapidly-rising jökulhlaup cycle at the A.P. Olsen Ice Cap, NE-Greenland
}

\section{Paper}

Cite this article: Behm M et al. (2020). Seismic characterization of a rapidly-rising jökulhlaup cycle at the A.P. Olsen Ice Cap, NE-Greenland. Journal of Glaciology 66(256), 329-347. https:// doi.org/10.1017/jog.2020.9

Received: 19 December 2019

Revised: 10 January 2020

Accepted: 13 January 2020

First published online: 4 February 2020

Keywords:

Jökulhlaups (GLOFs); seismology; subglacial processes

Author for correspondence:

Michael Behm,

E-mail: michael.behm@ou.edu (c) The Author(s) 2020. This is an Open Access article, distributed under the terms of the Creative Commons Attribution-

NonCommercial-ShareAlike licence (http:// creativecommons.org/licenses/by-nc-sa/4.0/), which permits non-commercial re-use, distribution, and reproduction in any medium, provided the same Creative Commons licence is included and the original work is properly cited. The written permission of Cambridge University Press must be obtained for commercial re-use.

\author{
Michael Behm ${ }^{1}$ (D), Jacob I. Walter ${ }^{2}$ (D), Daniel Binder ${ }^{3,4,5}$ (D), Feng Cheng ${ }^{6}$ (D), \\ Michele Citterio ${ }^{4}$, Bernd Kulessa ${ }^{7}$, Kirsty Langley ${ }^{8}$, Phillipe Limpach ${ }^{9}$, \\ Stefan Mertl ${ }^{10}$, Wolfgang Schöner ${ }^{11,5}$, Mikkel Tamstorf ${ }^{12}$ and Gernot Weyss ${ }^{3,5}$
}

${ }^{1}$ School of Geosciences, University of Oklahoma, Norman, USA; ${ }^{2}$ Oklahoma Geological Survey, University of Oklahoma, Norman, USA; ${ }^{3}$ Climate Section, ZAMG - Central Institute for Meteorology and Geodynamics, Vienna, Austria; ${ }^{4}$ Glaciology and Climate Department, GEUS - Geological Survey of Denmark and Greenland, Copenhagen, Denmark; ${ }^{5}$ Austrian Polar Research Institute (APRI), Wien, Austria; ${ }^{6}$ Lawrence Berkeley National Laboratory, Berkeley, USA; ${ }^{7}$ Glaciology Group, Swansea University, UK; ${ }^{8}$ Greenland Survey, ASIAQ, Nuuk, Greenland; ${ }^{9}$ Institute of Geodesy and Photogrammetry, ETH Zurich, Zurich, Switzerland; ${ }^{10}$ Mertl Research GmbH, Vienna, Austria; ${ }^{11}$ Institute of Geography and Regional Research, Graz University, Graz, Austria and ${ }^{12}$ Department of Bioscience, Aarhus University, Aarhus, Denmark

\section{Abstract}

Rapidly-rising jökulhlaups, or glacial outburst floods, are a phenomenon with a high potential for damage. The initiation and propagation processes of a rapidly-rising jökulhlaup are still not fully understood. Seismic monitoring can contribute to an improved process understanding, but comprehensive long-term seismic monitoring campaigns capturing the dynamics of a rapidly-rising jökulhlaup have not been reported so far. To fill this gap, we installed a seismic network at the marginal, ice-dammed lake of the A.P. Olsen Ice Cap (APO) in NE-Greenland. Episodic outbursts from the lake cause flood waves in the Zackenberg river, characterized by a rapid discharge increase within a few hours. Our 6 months long seismic dataset comprises the whole fill-anddrain cycle of the ice-dammed lake in 2012 and includes one of the most destructive floods recorded so far for the Zackenberg river. Seismic event detection and localization reveals abundant surface crevassing and correlates with changes of the river discharge. Seismic interferometry suggests the existence of a thin basal sedimentary layer. We show that the ballistic part of the first surface waves can potentially be used to infer medium changes in both the ice body and the basal layer. Interpretation of time-lapse interferograms is challenged by a varying ambient noise source distribution.

\section{Introduction}

\subsection{Background and motivation}

Ice is a crystalline solid-state material exhibiting both ductile and brittle deformation under tensile stress loading (Schulson and Duval, 2009). Glaciers can be seismically active, exhibiting a variety of temporally and spatially clustered events, caused by a broad range of source mechanisms (West and others, 2010; Brueckl and others, 2015; Podolskiy and Walter, 2016; Aster and Winberry, 2017). Myriad studies have linked glacial seismicity to glacier motion either directly or indirectly during the formation or deepening of crevasses, and to subglacial hydrology (VanWormer and Berg, 1973; Deichmann and others, 1979; Weaver and Malone, 1979; Metaxian and others, 2003; Walter and others, 2008; Allstadt and Malone, 2014; Bartholomaus and others, 2015; Vore and others, 2019). In the sub-polar regions, the seasonal variation of glacier motion is closely related to the transient water input and the apparent subglacial drainage system capacity. A commonly cited model for glacier motion includes the notion that transient water input rates exceed the capacity of the subglacial drainage system, which increases the basal water pressure and results in enhanced basal motion of the glacier (Iken and Bindschadler, 1986; Anderson and others, 2004; Bartholomaus and others, 2008; Schoof, 2010). The sudden ice motion can be seismogenic, producing a so-called 'icequake'. Early passive seismological experiments on glaciers yielded insight into the nature of icequakes, interpreting the opening of surface crevasses as the main seismic source of events (Neave and Savage, 1970). Deichmann and others (2000) reported deep icequakes from below the brittle-to-ductile transition, recorded at the Unteraargletscher $(\mathrm{CH})$. Helmstetter and others (2015) deduced hydro-fracturing as seismic source mechanism of events below the brittle-to-ductile transition of a temperate glacier.

Boon and Sharp (2003) observed hydrologically-driven ice fracturing on a cold, Arctic glacier which established a surface-bed connection. Rapid supraglacial lake drainage events on the Greenland Ice Sheet initiated hydrologically-driven surface-bed connections through km-thick, cold ice (Das and others, 2008; Doyle and others, 2013; Jones and others, 2013; Carmichael and others, 2015; Dow and others, 2015). These drainage events coincided with increased seismicity, transient acceleration, ice-sheet uplift and horizontal displacement. 
Hence, water can potentially be found at all depths of temperate, polythermal and cold-based glaciers and ice sheets, and hydrologically-driven ice fracturing is a widespread and efficient mechanism to propagate englacial and subglacial drainage systems (e.g. Fountain and others, 2005; van der Veen, 2007; Benn and others, 2009; Harper and others, 2010; Tsai and Rice, 2010).

The Icelandic term jökulhlaup describes a sudden release of water from a glacier, also commonly referred to as a glacial outburst flood. The discharged water can be stored in ice-marginal, subglacial, englacial and supraglacial locations, although volcanogenic and rainfall-induced floods can occur without significant water storage (Roberts, 2005). Jökulhlaups are an episodic, but common phenomena for glacierized regions like Greenland and span a broad range of flood volume and frequency (e.g. Tweed and Russell, 1999; Mayer and Schuler, 2005; Weidick and Citterio, 2011; Larsen and others, 2013; Carrivick and others, 2017; Grinsted and others, 2017). The classic jökulhlaup theory (Nye, 1976; Spring and Hutter, 1981, 1982; Clarke, 1982) assumes a pre-existing conduit with a constant potential gradient, which pipes the water through the glacier. Two competing processes determine the varying conduit cross-section and consequently, the proglacial discharge. Friction between floodwater and the conduit wall, as well as the initial water heat content enlarge the conduit cross-section through melting, whereas ice creep driven by the overburden pressure reduces the cross-section. Water pressure in the conduit is assumed not to exceed the ice overburden pressure. The classic jökulhlaup model reproduces proglacial discharge curves characterized by an exponential-like discharge increase over days and weeks.

The 1996 jökulhlaup of the subglacial lake Grímsvötn under the temperate Vatnajökull ice cap showed an exceptionally high maximum discharge reached in just $\sim 16 \mathrm{~h}$ after the initial glacier terminus burst out (Snorrason and others, 1997). This rapidly-rising jökulhlaup cannot be explained by the classic jökulhlaup theory, and hydro-fracturing is assumed to be a fundamental process of this type of jökulhlaup (Roberts and others, 2000; Flowers and others, 2004; Björnsson, 2011). Jóhannesson (2002) suggested a subglacial pressure wave forcing a pathway for the subsequent floodwater discharge for the 1996 Grímsvötn jökulhlaup. A necessary condition for the pressure wave initiation is, in contrast to the classic jökulhlaup theory, a basal water pressure that locally exceeds the overburden pressure (glaciostatic stress). Several following reports showed that rapidly-rising jökulhlaups are often observed (e.g. Einarsson and others, 2016, 2017), and can also occur in non-volcanic environments outside of Iceland (e.g. Grinsted and others, 2017).

Increased microseismic activity in temporal and spatial clusters is observed during jökulhlaups (Walter and others, 2010). Walter and others (2009) linked the vast majority (>99\%) of the detected seismic events to shallow tensile faulting due to the opening of surface crevasses for the 2004 Gornerlake $(\mathrm{CH})$ jökulhlaup. Less than $0.5 \%$ of the events could be located below the crevassing zone. Moment tensor analysis yielded a tensile crack source with steeply dipping fault planes for the intermediate depth $(\sim 100 \mathrm{~m})$ events, and a tensile fracturing source with a near-horizontal, bed-parallel, fault plane for the basal events (Walter and others, 2010). Contrary to their expectation, the detected basal events correlated with decreasing and minimum basal water pressures. Walter and others $(2008,2010)$ interpreted them as the collapse of cavity roofs during periods of low basal water pressure. They found no evidence that subglacial routing of the lake water caused brittle deformation radiating seismic energy during active flooding. However, the 2004 Gornerlake outburst showed rather the characteristics of a classic jökulhlaup with an exponential proglacial discharge increase over days.
In this paper, we present results of a seismic monitoring campaign during the 2012 fill-and-drain cycle of an ice-dammed lake. The lake is dammed by the predominantly cold-based A. P. Olsen Ice Cap (APO), NE-Greenland, and features a quasi-annual filland-drain cycle. The 2012 outburst event featured a rapidly-rising discharge and was one of the most destructive APO jökulhlaups observed so far. To our knowledge, this is the first 'on-ice' seismic monitoring in the path of a rapidly-rising jökulhlaup, covering a full fill-and-drain cycle. Our study aims at describing first-order observations of the spatiotemporal variation of seismicity and discusses the potential of seismic interferometry to monitor medium changes during a jökulhlaup as well as the ambiguities in interpretation. Furthermore, the relationships between seismicity and relevant environmental data (air temperature, river discharge, snow depth, precipitation) are presented and discussed.

\subsection{Study site}

In 1995, the Zackenberg Research Station (ZRS; $74^{\circ} 28^{\prime} \mathrm{N}$, $20^{\circ} 34^{\prime} \mathrm{W}$; Fig. 1) was established in the National Park of Northeast Greenland. The Zackenberg region is the longestserving study site of the 'Greenland Ecosystem Monitoring' program (GEM, www.g-e-m.dk; Albon and others, 2014). This high-Arctic setting has an annual mean temperature of $-9.0^{\circ} \mathrm{C}$ (mean over 1996-2013) and experiences positive monthly mean temperatures only in June, July, August and September (data.ge-m.dk). The mean annual precipitation is $211 \mathrm{~mm}$ (mean over 1996-2013), predominantly as snow during winter (Jensen and others, 2014). Regular flood waves from jökulhlaups have been recorded for the Zackenberg river since the hydrometric monitoring at the research station was installed in 1996. River discharge is continuously measured as part of the GEM sub-programmes ClimateBasis and GeoBasis (www.g-e-m.dk). The river catchment covers $514 \mathrm{~km}^{2}$, of which, $106 \mathrm{~km}^{2}$ are covered by glaciers and ice caps (Fig. 1). The river catchment receives no discharge contribution from the Greenland Ice Sheet. Discharge data yield typical summer values in the range of $10-60 \mathrm{~m}^{3} \mathrm{~s}^{-1}$ (Søndergaard and others, 2015), though the episodic jökulhlaups show maximum discharges of $\sim 100-250 \mathrm{~m}^{3} \mathrm{~s}^{-1}$. Generally, the jökulhlaup hydrograph is characterized by a rapidly increasing discharge over just a few hours. The whole flood event takes about half a day. The 2012 flood wave on August 6 was one of the largest observed so far, triggering substantial erosion of the riverbanks and bed. The hydrometric station was destroyed, and consequently, it was not possible to completely measure the 2012 flood discharge. The estimated 2012 peak discharge of $215 \mathrm{~m}^{3} \mathrm{~s}^{-1}$ is considered a minimum value (Personal communication J. Abermann).

Jökulhlaups originate from a marginal, ice-dammed lake, impounded by the southeast outlet glacier of the A.P. Olsen Ice Cap (APO, $74^{\circ} 38^{\prime} \mathrm{N}, 21^{\circ} 26^{\prime} \mathrm{W}$; Fig. 1). The predominantly coldbased APO is a peripheral ice cap in the northeast of Greenland, $\sim 35 \mathrm{~km}$ inland of the research station, exhibiting maximum ice depths of $\sim 350 \mathrm{~m}$ (Binder and others, 2013). On the occasion of the fourth International Polar Year, the GlacioBasis monitoring program (www.g-e-m.dk) was initiated in order to quantify the APO mass balance. GlacioBasis operates in total three automated weather stations (AWSs, Fig. 2) on the APO. The mean specific mass balance of $\sim-0.5 \mathrm{~m}$ w.e. correlates with an equilibrium line altitude ranging between 1100 and $1300 \mathrm{~m}$ a.s.l. (Larsen and others, 2015). The southeast outlet glacier dams an adjacent, ice-free side valley $(\sim 1.5 \times 0.5 \mathrm{~km})$ where water accumulates and forms the lake A. P. Olsen (LAPO, Fig. 1). The lake is regularly drained by jökulhlaups with a quasi-annual cycle. The maximum lake volume varies between the individual jökulhlaup events and is in the range $8-16 \times 10^{6} \mathrm{~m}^{3}$. Generally, the lake fill-and-drain cycle starts with the melt season in May/June and ends between early July and 


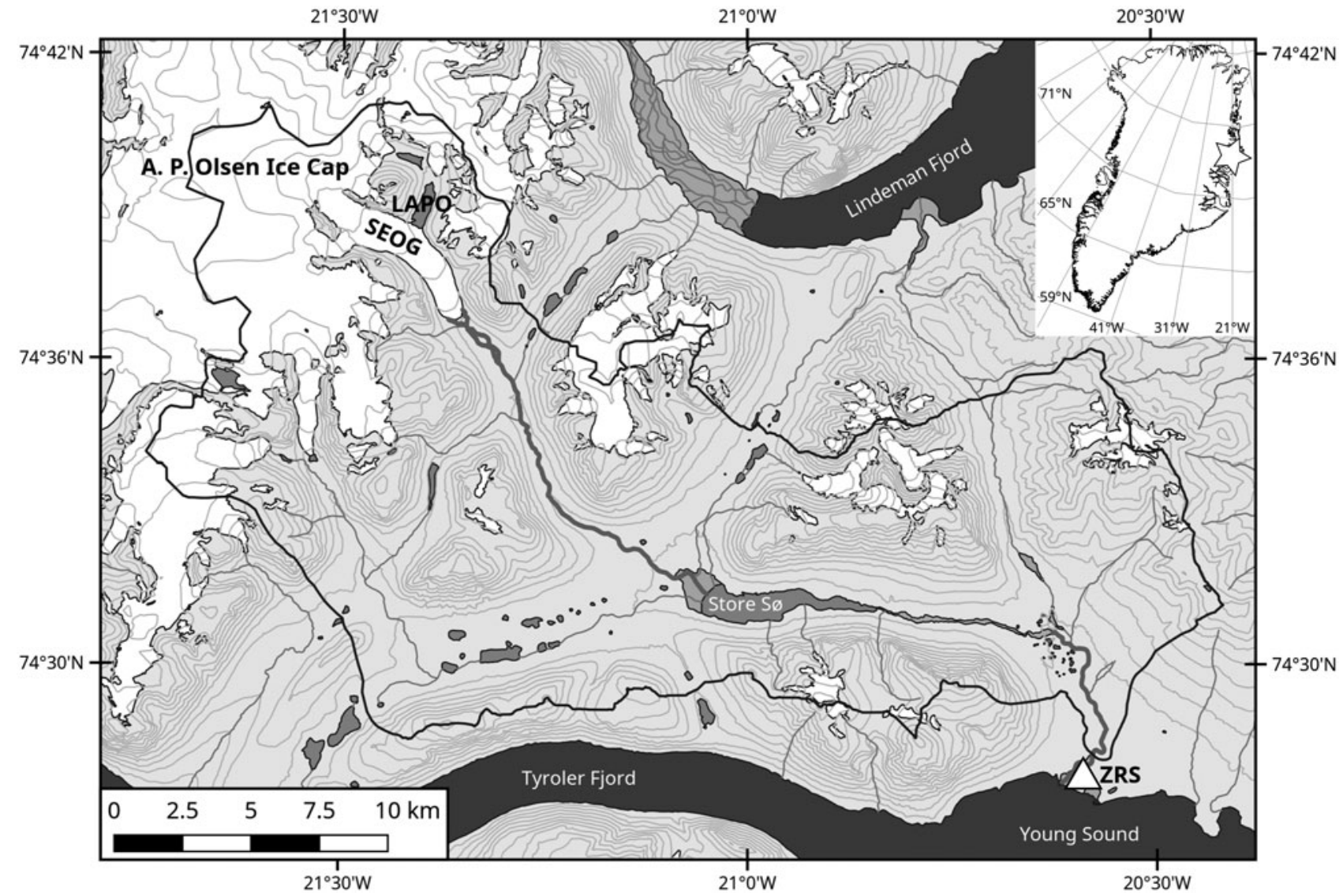

Fig. 1. The A.P. Olsen Ice Cap is $\sim 35 \mathrm{~km}$ inland from the Zackenberg Research Station (ZRS, white triangle). The origin of the recurring flood waves is an icemarginal lake (LAPO) dammed by the Southeast outlet glacier (SEOG) of the A. P. Olsen Ice Cap. On its route from the SEOG terminus to the ZRS, where the water drains into the Young Sound, the flood wave passes the Store Sø ('Large Lake'). The black line encircles the entire river catchment basin.

the first months of the consecutive year. Based on the existing time series, jökulhlaups are most probable for August. On its way downstream from the APO to the research station, the river runs through the Store Sø ('Large Lake', Fig. 1). The lake has an area of $\sim 4.4 \mathrm{~km}^{2}$ and likely dampens the outburst hydrograph. However, recorded discharge data at the station still show the characteristics of a rapidly-rising jökulhlaup. Since 2008 an automated camera (Fig. 2), as part of the GeoBasis program, provides one daily photograph of the lake, and thus, one inferred water-level estimate. Additionally, a pressure sensor (Fig. 2) installed in 2013 records the lake water level, showing that the 2013 and 2016 jökulhlaups started at water levels of $\sim 27$ and $40 \mathrm{~m}$, respectively. However, water-level measurements from this sensor were not available for the 2012 jökulhlaup described in this paper.

\subsection{Seismic monitoring network}

The seismic monitoring network was installed in April 2012 when the lake water level was zero. The continuous recording seismic network consisted of five locations in the ablation zone of the outlet glacier. All sensors were installed in shallow boreholes $(\sim 3 \mathrm{~m})$ and were covered with a geotextile to reduce ablation rates by up to 50\% (Olefs and Lehning, 2010). Two locations were designed as tripartite arrays (APO4, APO5), and the remaining three locations (APO1, APO2, APO3) were equipped with three-component sensors (Fig. 2). The tripartite arrays have a radius of $12 \mathrm{~m}$ and are equipped with vertical geophones. All sensors have a characteristic frequency of $4.5 \mathrm{~Hz}$ (Geospace GS-11D) and are attached to a Reftek 130 recorder with a sampling frequency of $500 \mathrm{~Hz}$. The power supply of the monitoring stations consists of a combination of solar panels $(2 \times 20$ Watts $)$ and a vertical wind turbine
(Leading Edge v50) charging batteries. The maximum interstation distance is $1200 \mathrm{~m}$. After the installation of the monitoring network, a ground-penetrating radar (GPR) survey was conducted which found ice thicknesses in the range of 50 to $220 \mathrm{~m}$ for the monitoring site (Fig. 2). In 2012, the seismic network operated between May and November. All stations (APO1-AP05, Fig. 2) recorded continuously over the entire period, except for $2 \mathrm{~d}$ at the beginning of July.

\section{Methodology}

\subsection{Discrete icequake analysis: event detection, classification and location}

In the early pre-flood stage, only a few seismic events occur, with some expression of tremor-like events (e.g. Pomeroy and others, 2013; Heeszel and others, 2014) that are characterized by a duration of up to several minutes with frequencies up to $50 \mathrm{~Hz}$. Upon visual inspection, the majority of the events appeared as a sequence of body and surface waves (Fig. 3), suggesting surface crevassing as a likely possible source (e.g. Deichmann and others, 2000; Mikesell and others, 2012). The surface-wave peaks occur at frequencies between 5 and $30 \mathrm{~Hz}$ and seem to interfere with later scattered surface-wave arrivals. Different arrival times at the two horizontal components suggest the existence of both Rayleigh and Love waves. We first detect icequakes and then use a wavetype discriminator based on the waveform polarization observed at a centrally located three-component station. Results from these initial analyses suggested that a vast majority of icequakes were surface waves and so we detail a simplified 2-D location algorithm to locate sources based on the surface-wave arrival times. 


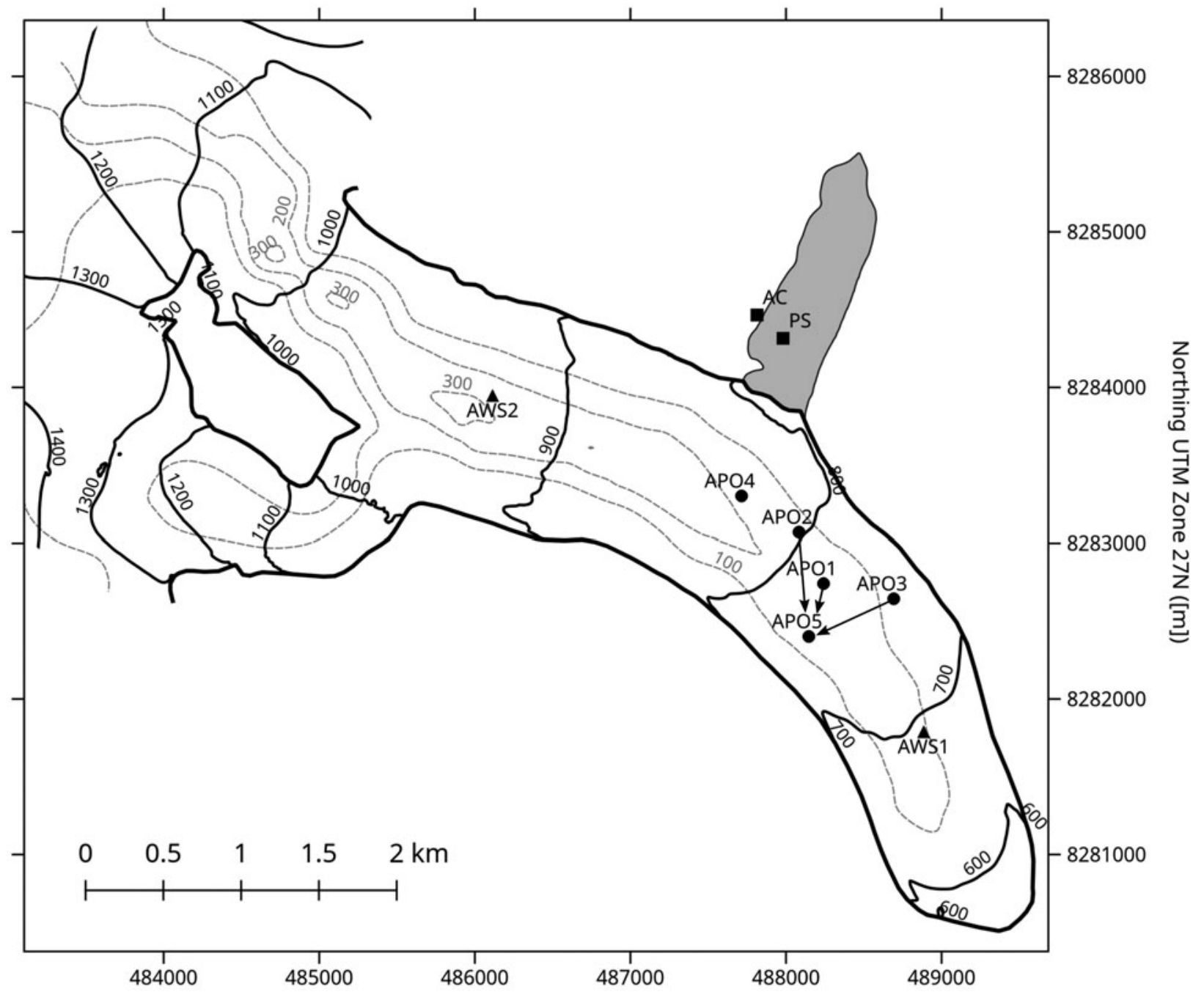

Easting UTM Zone $27 \mathrm{~N}([\mathrm{~m}])$

Fig. 2. Seismic monitoring network (APO1-APO5) on the South East outlet glacier. Interstation arrows indicate seismic interferometry sections shown in Figure 10. AWS1, AWS2: GlacioBasis automated weather stations. The ice-dammed lake is indicated by the grey area. The GeoBasis automated camera (AC) takes one photo per day. In 2013, a pressure sensor (PS) was installed to log the lake's water depth. Contour lines of the ice thickness based on GPR data are shown (dashed grey line). Solid thick black line represents the glacier's outline, including the rock outcrop in the upper part.

\subsubsection{Event detection}

In order to identify individual icequakes, we remove the GS-11D instrument response to simulate ground motion and bandpass the waveforms between 1 and $20 \mathrm{~Hz}$. We implement a standard shortterm average/long-term average (STA/LTA) transformation of each of the time series for each vertical component geophone in the array, with the short-term window at $2 \mathrm{~s}$ and the long-term window at $20 \mathrm{~s}$. The ratio of STA/LTA essentially forms a new time series that triggers a possible candidate event if that transformed signal rises above a threshold of four times the median daily STA/LTA ratio and that trigger ends when the transformed signal falls below two times the median daily STA/LTA ratio. If eight sensors simultaneously trigger with the aforementioned STA/LTA thresholds, then we have a candidate event and we additionally determine the time at which each of the sensors triggered, which informs our location estimates.

\subsubsection{Event-type discrimination}

We arrange the trigger times relative to those sensors that triggered first and fit a line to the travel-time plotted with respect to the inter-sensor distance relative to which sensor triggers first, irrespective of the network geometry so that the distance is calculated as the distance from that sensor to the first triggered sensor. The reciprocal of the slope of the fitted line is an estimate of the apparent wave speed as the wave moves across the glacier array. A histogram of these values indicates a strong peak near $\sim 1500 \mathrm{~m} \mathrm{~s}^{-1}$, which would be consistent with predominantly surface waves triggering our sensors. Note that the value corresponds to an apparent velocity across the array and would not be the actual surface-wave velocities, but rather close. Also, compared to other studies (e.g. Mikesell and others, 2012), this velocity appears to be low. However, our interferometric analysis in the next section suggests that surface-wave velocities in that frequency range comprise the effects of both ice and basal sediments. Some of the stations comprising the network included three-component geophones (APO1-APO3). We can utilize the polarization of the waveforms to further discriminate the type and distinguish between body and surface waves. A frequency-based polarization test has also recently been utilized for a glaciological study with the so-called glaciohydraulic tremor (Vore and others, 2019). For the incoming waves to the three-component station, the rectilinearity (also commonly referred to sometimes as simply 'linearity'), dip and azimuth can be determined based on the analysis of the data within discrete windows, if the three components on the sensor are orthogonal to one another. We generally follow the methods described in Baillard and others (2014). We 


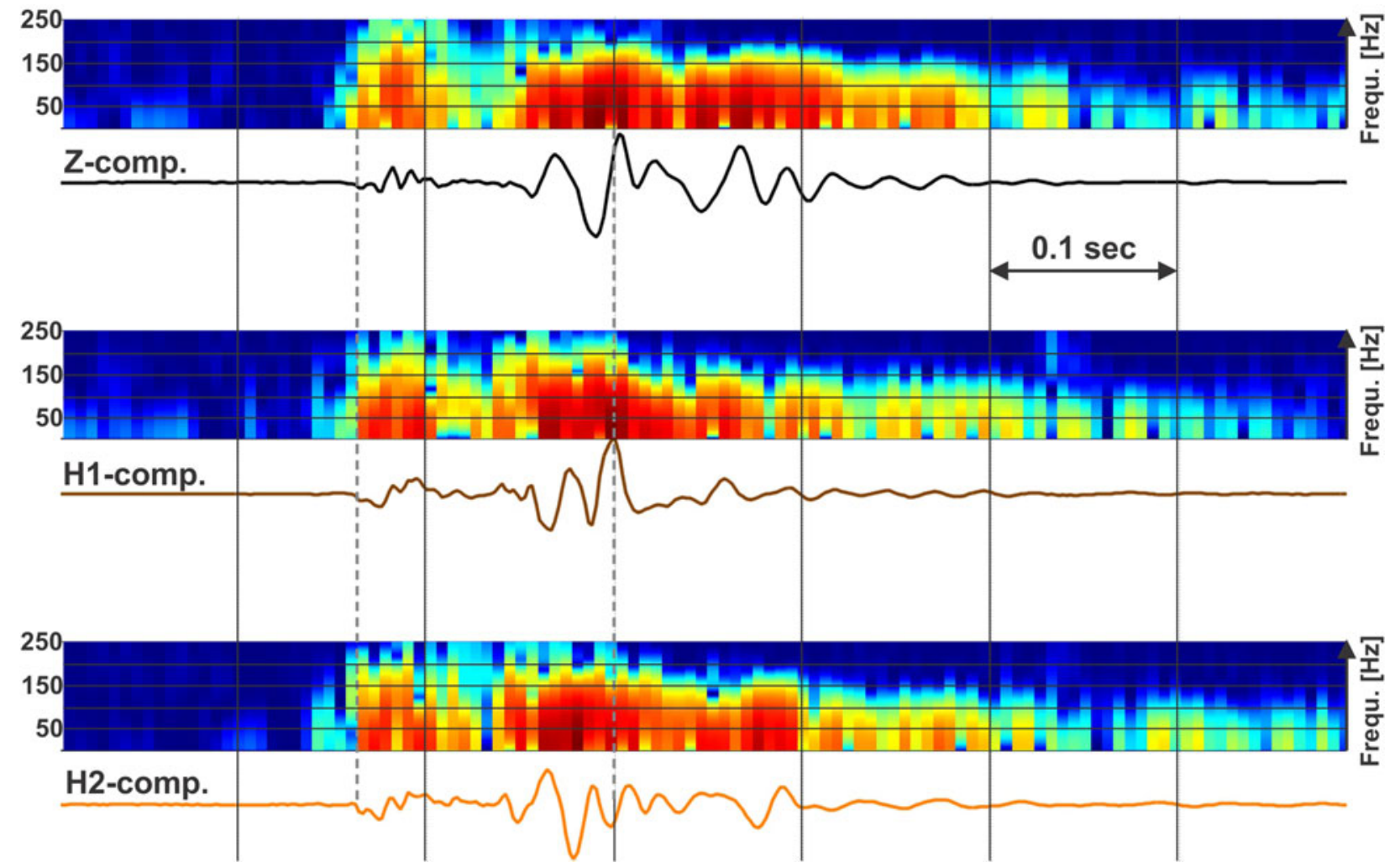

Fig. 3. A typical seismic event in the syn-discharge phase (6/1/2012) recorded on the 3C-station APO3 with spectrograms on top. H1 is oriented towards the flow direction of the glacier (ca. SE), and $\mathrm{H} 2$ is oriented $90^{\circ}$ clockwise to $\mathrm{H} 1$. The left, dashed vertical line indicates the onset of a body wave, and the dashed line on the right is aligned with the strongest positive peak in the following Rayleigh surface-wave arrival. Note that the surface wave appears earlier on the $\mathrm{H} 2$ component, suggesting the superposition of Love waves.

first compute the $3 \times 3$ covariance matrix across the samples with a sliding window of $0.5 \mathrm{~s}$. We arbitrarily define the window length to be short enough to capture local short duration waveforms but with sufficient length for the polarization test.

Ordered eigenvalues determined from the covariance matrix are used to compute the azimuth, dip or otherwise known as incidence angle (Vidale, 1986), and rectilinearity (Jurkevics, 1988). We compute the azimuth, or commonly referred to as backazimuth, of the incoming seismic energy within a window by computing the arctangent of the largest eigenvalue. We refer to the azimuth portion of the polarization analysis later as it further informs directionality of the incoming waves regardless of whether we detect them with the location algorithm outlined in the next section.

Rectilinearity approaching a value of 1 would indicate a body wave. In addition, $\mathrm{P}$ waves would have near-vertical incidence (dip $\sim 90^{\circ}$ ), while $S$ waves would be polarized horizontally (dip $\sim 0$ ). To combine these basic physical properties into a discrimination tool, Baillard and others (2014) proposed a dip-rectilinearity function (DR) that was used to characterize whether signals were body or surface waves at sample $k$. The function is such that:

$$
\begin{aligned}
\mathrm{DR}= & \text { Rectilinearity }(\mathrm{k}) \\
& \times \operatorname{sign}[a \times \sin ([\operatorname{Dip}(\mathrm{k})])-\operatorname{Rectilinearity}(\mathrm{k})],
\end{aligned}
$$

where $a$ is an arbitrary weight factor that we assign a value of 1.5 . When we analysed the entire study time period, only $\sim 3 \%$ of events had a DR score that would suggest the signal consists of body waves ( $D R>0.5)$. Thus, our use of the DR function informed an analysis decision to adapt a common earthquake location method in two dimensions. Figure 4 shows an example of rectilinearity (linearity), dip, azimuth and DR calculated for an arbitrary period of time when several icequakes occurred. About 420 s, several signals are present with rectilinearity $\sim 0.5$ and dip near zero which results in a DR score of $\sim-0.5$. The near-zero dip suggests either horizontally polarized S-waves or surface waves. Since the rectilinearity is not quite zero, the wave likely consists of a mix of S-wave and surface-wave polarization. The other visible icequake signals within the time period exhibit broadly similar characteristics. Thus, we conclude that most of the icequake signals consist of horizontally polarized waves, most likely surface waves.

Figure 5 shows a histogram of azimuth values derived from different hours during the study time period. This suggests that most of the wave energy is polarized parallel to the station-lake direction even when there are no detectable or visible icequakes in the record. Note that the sensors were aligned along the ice flow direction so that zero degrees azimuth would effectively be pointing southeast.

\subsubsection{Event location}

With observations of the arrival time at each station, we implement the classical iterative least-squares earthquake location inversion method, known as Geiger's method (Geiger, 1912). For a set of arrival times across a seismic network, Geiger's method seeks to iteratively minimize the travel-time residual between predicted and observed travel times. From linear algebra, the ordinary matrix is $\boldsymbol{d}=\boldsymbol{G} \cdot \boldsymbol{\delta} \boldsymbol{m}$, where $\boldsymbol{d}$ is a matrix composed of relative residuals between measured and predicted arrival times. $\boldsymbol{\delta} \boldsymbol{m}$ is a vector comprising the unknown updates to the initial model parameters, and $\boldsymbol{G}$ is the model matrix (see below). We make several simplifications to solve this problem. First, we only consider dimensions $x, y$ and $t$, which are locations and origin times of the icequakes. We exclude the $z$ dimension since we 

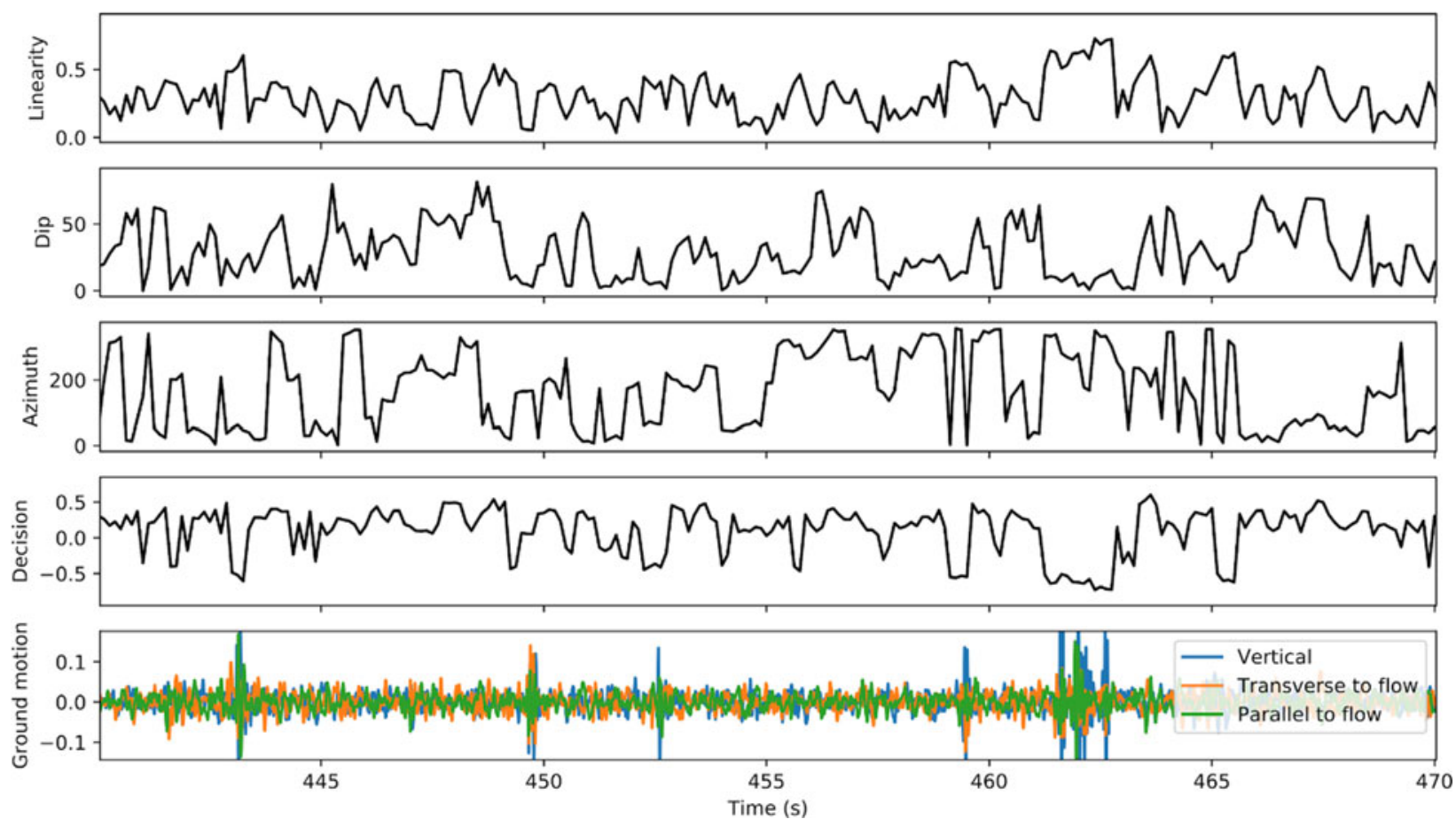

Fig. 4. Example of polarization test on a single station with panels including linearity (rectilinearity), dip (degrees), azimuth (degrees), decision dip-rectilinearity function (DR in the text) and the three components of ground motion $\left(\mathrm{m} \mathrm{s}^{-1}\right)$ from the seismometer at AP01. All seismometers were oriented relative to the glacier flow direction. The timescale is relative to seconds since the $0100 \mathrm{~h}$ on $25 / 6 / 2012$.

assume that the sources are located on the surface. Given an initial guess for $x$ and $y$ locations of the icequake and $t$ corresponding to the origin time for the initial location guess, at each iteration we compute

$$
d_{i}=t_{i}-t+\frac{1}{v} \sqrt{\left(x_{i}-x\right)^{2}+\left(y_{i}-y\right)^{2}}
$$

where $x_{i}$ and $y_{i}$ are the coordinates of the $i$-th sensor, $v$ is the velocity, which we assume to be $1600 \mathrm{~m} \mathrm{~s}^{-1}$ and $m$ is the model matrix consisting of $m=(t, x, y)^{T}$. The $\mathbf{G}$ matrix is composed of partial derivatives for each station-coordinate component arrival time. We simplify the $i \times 3$ matrix below.

$$
\begin{aligned}
G_{i}= & {\left[1,\left(x_{i}-x\right) / \sqrt{\left(x_{i}-x\right)^{2}+\left(y_{i}-y\right)^{2},}\right.} \\
& \left.\left(y_{i}-y\right) / \sqrt{\left(x_{i}-x\right)^{2}+\left(y_{i}-y\right)^{2}}\right] .
\end{aligned}
$$

Assuming that $m=m+\delta m$, we solve for $\delta m$ and update $m$ at each iteration, where $\delta m$ is

$$
\delta m=\left(G^{T} G\right)^{-1} G^{T} d .
$$

If we had additional phases (P and S), stations and were containing the vertical direction $(\mathrm{z})$, we might iterate until the residual between the predicted arrival time and actual arrival time fell below a quality threshold. Since we have a more poorly constrained dataset, we simply iterate ten times and compute the std dev. of the station residuals to report how well-constrained the locations might be.

\subsection{Seismic interferometry}

In the most general sense, seismic interferometry can be considered as a process to synthesize wavefields through the correlation of other, e.g. recorded, wave fields (Schuster, 2009; Wapenaar and others, 2010a, 2010b; Galetti and Curtis, 2012). It allows one to reconstruct seismic waves travelling between two receiver stations by turning one of the receivers into a virtual source (Bakulin and Calvert, 2006), and thus sometimes is also referred to as empirical Green's function (EGF) retrieval. Ambient seismic noise interferometry relies on the abundance and potentially broad frequency spectrum of natural and anthropogenic sources of seismic energy. The location and origin times of these sources do not need to be known, but their spatial distribution must satisfy the stationary phase condition with regard to the receiver geometry (Snieder, 2004; Snieder and others, 2006). In essence, this condition states that the travel paths from the ambient seismic noise source to the two receiver stations must be identical up to the receiver where the energy arrives first. With this condition met, the kinematic path effects outside the receiver deployment are eliminated in the correlation process. In the case of surface stations, the EGF is often dominated by surface waves (Forghani and Snieder, 2010), although several studies extract body waves from dense deployments (e.g. Roux and others, 2005; Draganov and others, 2009; Nakata and others, 2015). Therefore, surface-based seismic imaging using interferometry mostly involves the retrieval and inversion of surface-wave dispersion for shear-wave velocity models (Bensen and others, 2007; Behm and others, 2014; Hannemann and others, 2014; Cheng and others, 2018, 2019). The sensitivity of the EGF to small medium changes with time has been demonstrated in different environments and at different scales (e.g. Sens-Schönfelder and Wegler, 2006; Nakata and Snieder, 2012; Hillers and others, 2015a, 2015b; Larose and others, 2015; Planes and others, 2015), although the variability of the ambient noise source distribution and characteristics can challenge the interpretation of temporal subsurface changes (Tsai, 2009; Froment and others, 2010; Fichtner, 2014; Behm, 2017).

The application of interferometry on glaciers on a local scale is still a novel approach and only a relatively small number of publications exist. Overviews are included in Aster and Winberry 

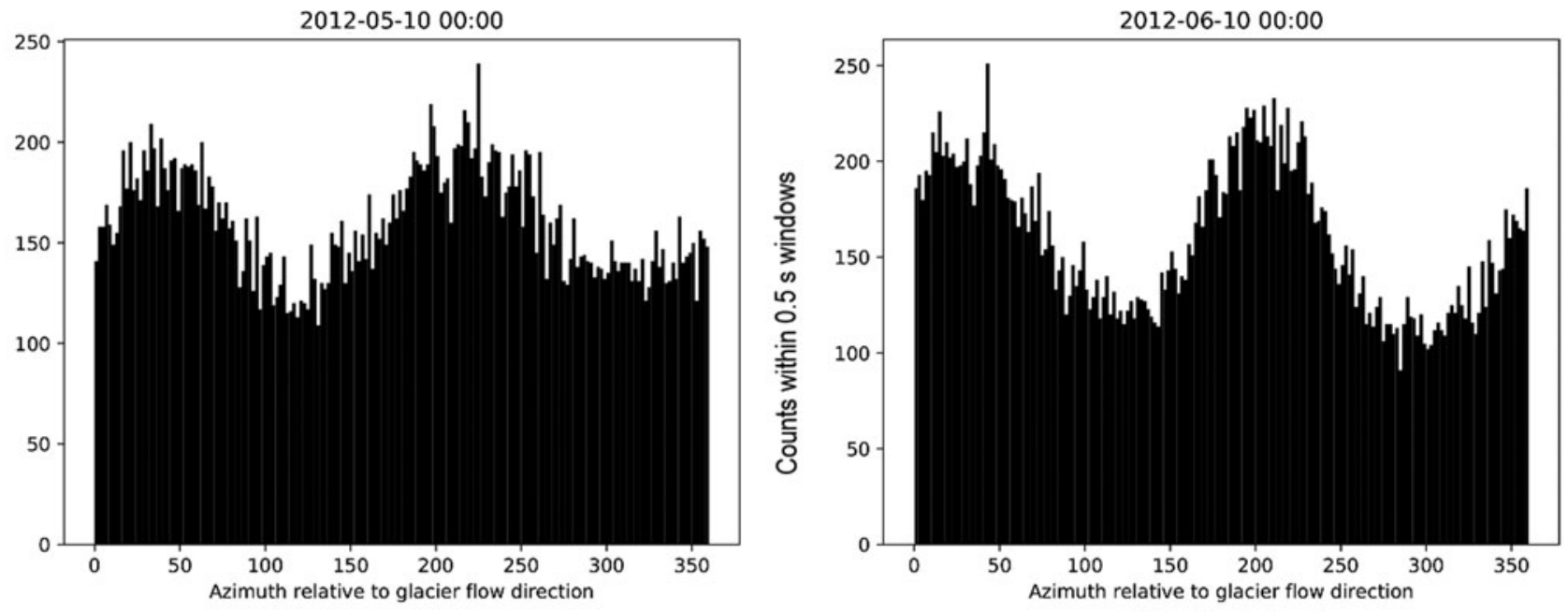

2012-08-07 00:00
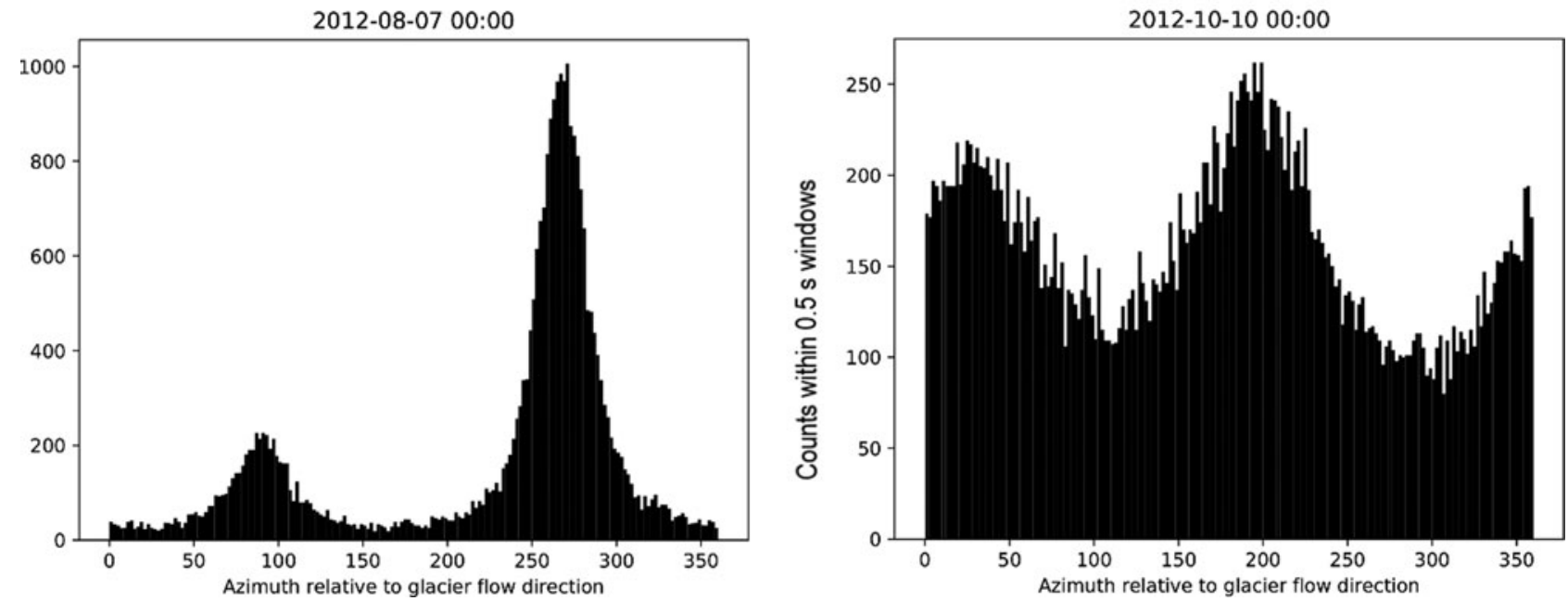

Fig. 5. Histogram of the azimuth estimates from the polarization analysis at AP01 for each $0.5 \mathrm{~s}$ time window over an hour-long starting at the time period indicated at the top of the panel. An example of the continuous estimation of azimuth from the polarization analysis is also shown in Figure 4. The figure suggests strong clustering in $\sim 30^{\circ}$ and $\sim 210^{\circ}$, with the exception of the bottom left panel, which is during the jökulhlaup. Hourly histograms are computed and rotated vertically for the image in Figure 12

(2017) and Podolskiy and Walter (2016). The latter point out that the overall homogeneous glacial environment usually limits the generation of scattered coda waves, which are commonly used in the context of 4D interferometric monitoring (Snieder, 2006). Walter and others (2015) show how interferometry applied to selected and located events can be used to monitor seismic propagation velocity changes with an accuracy of $0.1 \%$ for glacier ice. Based on interferometry, Zhan (2019) detects seismic anisotropy in surface waves during the 2008-2011 active phase of the surge-type Bering glacier. He related the seismic anisotropy to basal crevasse development during the switch from a channelized to a distributed subglacial discharge system.

Our workflow starts with cutting the continuous data of the entire monitoring period into $1 \mathrm{~h}$ segments and resampling to $80 \mathrm{~Hz}$. Temporal normalization using Automatic Gain Control (AGC) with a window length of $0.2 \mathrm{~s}$ and spectral whitening in the band $1-35 \mathrm{~Hz}$ is applied. Finally, interferograms are calculated for all station pairs and all components (Z-Z, T-T, R-R) using cross-coherence (Wapenaar and others, 2010b). Transverse (T) and radial ( $\mathrm{R})$ components are obtained by rotating the horizontal components to the virtual source - receiver pair direction prior to interferometry. Due to the sparse station distribution with limited offset variation, we stack all interferograms in offset bins (bin size $200 \mathrm{~m}$ ) to derive one representative virtual source gather for each component. Prior to stacking, the traces are time-shifted with a linear move-out (LMO) correction for a velocity of $1500 \mathrm{~m} \mathrm{~s}^{-1}$ to account for differential offsets within each bin. Each stacked trace is time-shifted back again with a reverse LMO, using the average of the offsets in the bin. Stacking also aims at simplifying and enhancing the subsurface response at the expense of spatial resolution. We stack causal and non-causal parts together as the different station pairs show a variable and complex pattern in terms of causal and non-causal arrivals. We also apply the same workflow to individual station pairs on consecutive $5 \mathrm{~d}$ intervals of continuous data to analyse the temporal variation of the interferograms.

\section{Results and discussion}

\subsection{Seismic events}

Initially, 108795 candidate events are identified using the STA/ LTA coincident trigger method described in Section 2.1.3. The temporal evolution of seismicity, expressed as a daily number of events and their amplitudes, and complementary environmental data are shown in Figure 6. Air temperature and snow depth data are from the GlacioBasis AWS2 (Fig. 2), while river discharge and precipitation data, provided by ClimateBasis and GeoBasis, are measured at the research station (Fig. 1). Based on the discharge curve from the Zackenberg river, we also arbitrarily define three time periods (pre-, syn-, post-discharge). The syn-discharge period is defined by a discharge rate larger than 


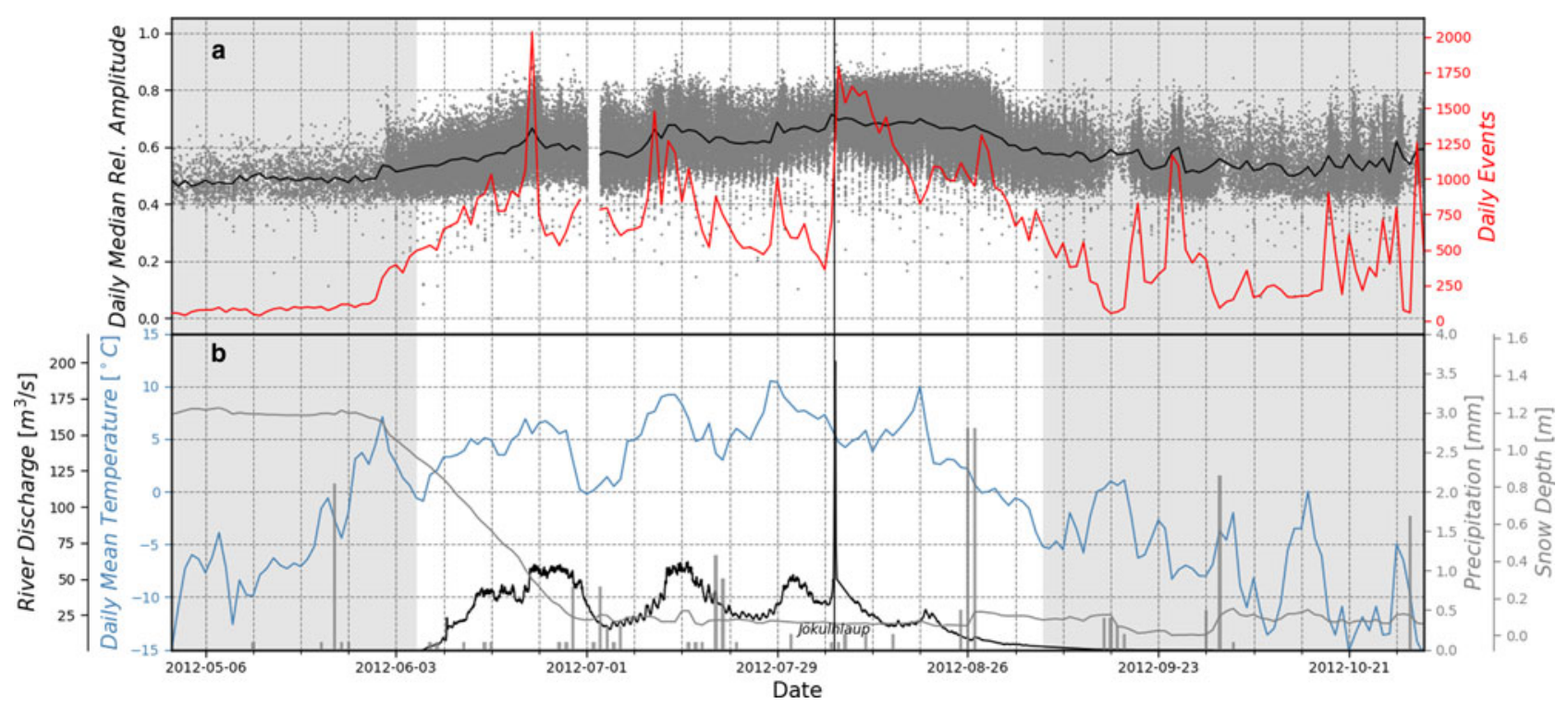

Fig. 6. Temporal evolution of seismicity. (a) Number of detected seismic events per day (red curve) and the corresponding event amplitudes (black curve; grey dots). (b) Air temperature (blue curve) and snow depth (grey curve) at station AWS2; Zackenberg river discharge (black curve) and precipitation (grey bars) at the Zackenberg research station. Grey background: pre- and post-discharge periods corresponding to a discharge $<1.75 \mathrm{~m}^{3} \mathrm{~s}^{-1}$.

$1.75 \mathrm{~m}^{3} \mathrm{~s}^{-1}$ (June 7-September 13) and lags the 2012 melt season by $\sim 1.5$ weeks.

Seismic activity gradually increases closer to the first period of positive temperatures towards the end of May. In the following 3 weeks until about mid of June we observe a steadily rising number of events per day which coincides with the depletion of the snow depth. During this period, we find no significant correlation between air temperature and the number of daily events. We associate this to meltwater retention by the initially cold snow cover. Throughout the spring and early summer, the depleting snow cover becomes temperate and meltwater retention volume continuously decreases, thus steadily increasing the meltwater fraction entering the glacial system. As a consequence, basal water pressure is building up and enhances basal sliding which leads to higher surface crevassing activity and seismicity.

The period with minimum snow depth and prior the jökulhlaup ( $\sim$ mid of June to beginning of August) is characterized by a correlation of seismicity, air temperature, precipitation and river discharge. An increase of seismicity is observed for three pre-jökulhlaup melt events, indicated by higher river discharges, as well as for single precipitation events. We find that discharge maxima trail the seismicity peaks with a time-lag of a few (4-8) days. In this period, the river discharge shows a clear diurnal cycle.

Seismicity picks up immediately with the jökulhlaup. Afterwards, a period of $\sim 3$ weeks with larger seismic amplitudes is observed, whereas the seismicity rate (number of events per day) declines overall. Following on hypotheses proposed by Walter and others $(2008,2010)$, we relate this period to the continuous collapse of the subglacial jökulhlaup drainage system. Walter and others (2008) observed a decline of seismicity for periods of high basal water pressure. They associated this observation to the buttressing effect of high water pressure in a collapsing drainage system. We can report a similar observation $\sim 2$ weeks after the jökulhlaup, where the last dominant melt event is accompanied by a drop of the seismicity rate. About three weeks after the jökulhlaup, a peak in the seismicity rate is observed which is preceded by the most intense rain event during the 2012 melt season. The corresponding seismic amplitudes remain high just until a few days after the rain event. In the following, we will discuss potential causes for the observed opposite behaviour of the seismicity rate just within 1.5 weeks.
Fudge and others (2009) reported of enhanced basal sliding rates and basal water variations initiated by an autumn rainstorm on Bench Glacier, Alaska, although equally large input events occurred in weeks prior with no apparent response. They relate this observation to the drainage system capacity decay in autumn which was intensified by the lack of water input during a 2-week period of cold and dry conditions that preceded the autumn event. In our case, the three post-jökulhlaup weeks are characterized by two competing processes. On the one hand, the gradual collapse of the channelized drainage system in the postjökulhlaup phase decreases the drainage system capacity, whereas substantial water supply due to the positive temperatures and several precipitation events maintains an efficient drainage system. However, we suggest that besides the gradual collapse of the jökulhlaup drainage system, the water input rate is the main driver of the observed opposite seismicity rate behaviour. The melt rate is determined by a rather smooth diurnal cycle, whereas the main rain event happened in just $\sim 3 \mathrm{~h}$ in the night from August 26 to 27 . While the meltwater input was conveyed by the current drainage system, the rainwater input rates exceeded the capacity of the collapsing drainage system. Consequently, basal water pressure built up and led to enhanced basal sliding and the observed increase of seismic events.

\subsection{Event localization}

Using the 2-D location algorithm we described previously, we were able to locate several events over the duration of 2012. Because of the limited number of stations, many of the icequakes could not be located accurately and so the localization only provides guiding evidence on the nature of the icequakes and is used in the context of interpretation of interferometry. Figure 7 shows the location of the events in the pre-, syn- and postdischarge periods. The syn-discharge period is additionally split up in the times before and after the jökulhlaup. Given the network limitations and resulting large residuals, we only chose $7.5 \%$ of the events and those within the glacier for the location plot. The selection of those events is based on their time residual and amplitude. However, this restriction does not bias the average spatial distribution or clustering of the events within any of the four time periods. In the pre-discharge period (Fig. 7a), we locate 

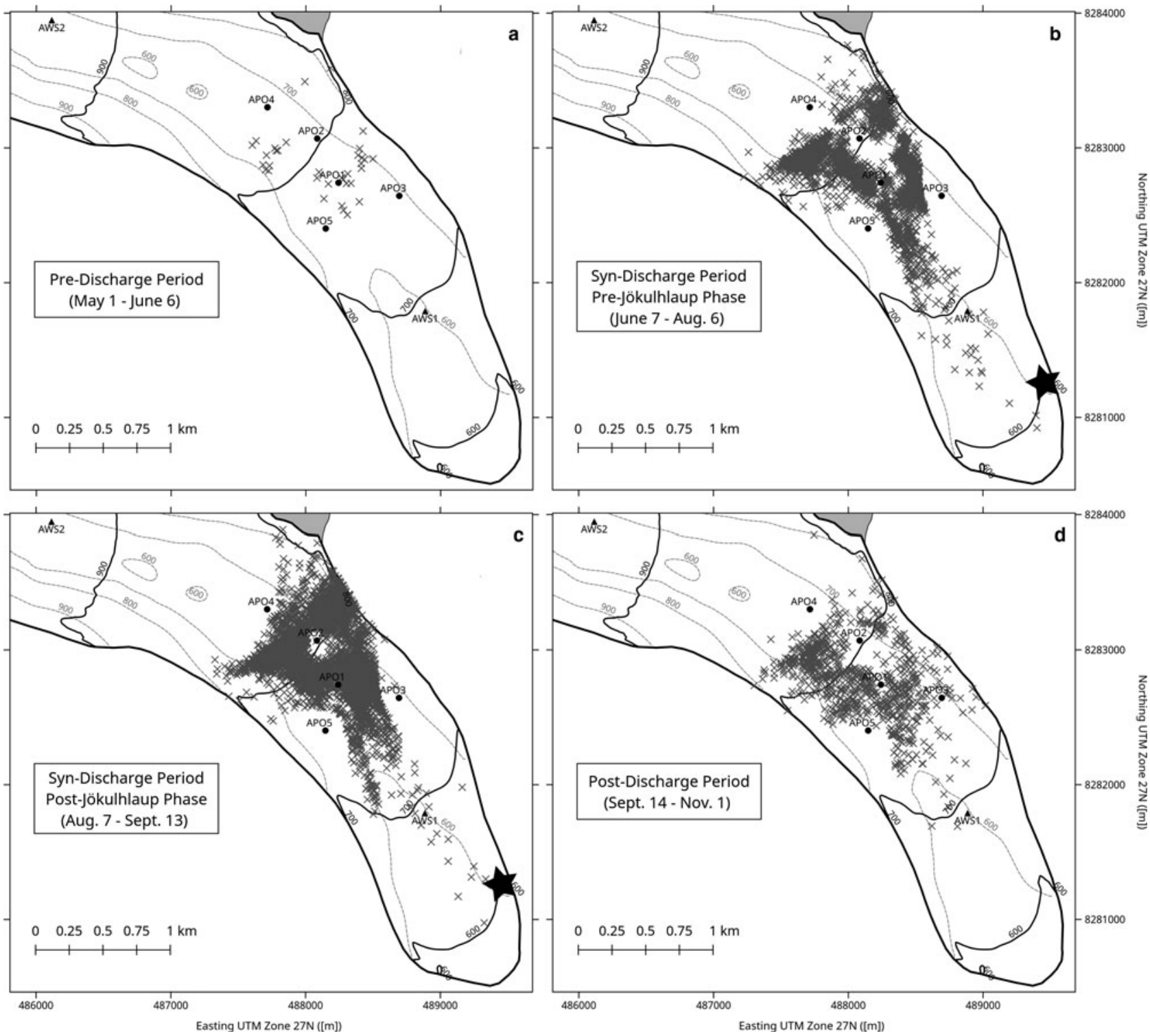

Fig. 7. Locations of seismic events in the pre-, syn- and post-discharge periods. The seismic events of the syn-discharge period are separately shown for the preand post-jökulhlaup phase. The black star indicates the main floodwater exit point. Only the events inside the glacier boundaries and with small residuals are shown. See text for details.

34 events within the glacier according to the selection criteria, which is in stark contrast to 7203 events during the syn-discharge period (Figs $7 \mathrm{~b}, \mathrm{c}$ ). In the post-discharge period, 817 glacier events are present and are concentrated within the seismic network (Fig. 7d). In all periods, most of the selected events are located inside the network. Only in the syn-discharge period, we find few events propagating further south towards the centre of the glacier snout, whereas syn-discharge events after the jökulhlaup show a tendency towards the south eastern glacier snout. The black star in Figure 7 indicates the observed main floodwater exit point as observed by eyewitnesses (Gernot Weyss (ZAMG), Kirstine Skov (GeoBasis)).

\subsection{Interferograms}

Figure 8 shows the offset-bin stacked interferograms of all station pairs. We observe two different move-outs in the gather, e.g. a high-frequency arrival with an apparent velocity of $\sim 1700 \mathrm{~m} \mathrm{~s}^{-1}$ and a low-frequency arrival with a velocity varying with offset. Velocities at larger offsets are $\sim 1400-1500 \mathrm{~m} \mathrm{~s}^{-1}$, and the velocities at short offsets appear to be lower. However, the interpretation of these low-frequency arrivals is challenged at short offsets, as the sidelobes of the causal and non-causal correlation functions begin to interfere. The frequency band is limited by the Nyquist frequency $(40 \mathrm{~Hz})$ after resampling, but generally, we do not observe any consistent arrivals in the interferograms at frequencies larger than $30 \mathrm{~Hz}$. This applies to both the stacked and pre-stack interferograms.

\subsection{Dispersion analysis of interferograms}

Dispersion analysis of surface waves retrieved through interferometry is a standard tool to analyse the depth variation of the shearwave velocity structure. Due to the limited number of stations, we initially apply a two-station method (frequency-time analysis; Keilis-Borok, 1989; Bensen and others, 2007) to derive group velocity dispersion between station pairs. We focus on the 3C station pairs (APO1, APO2, APO3) and again stack all dispersion curves (Fig. 9) to obtain an overall view on the data. The vertical component exhibits an expected behaviour in the frequency range $3-8 \mathrm{~Hz}$, but at higher frequencies, the velocities start to rise again. This is consistent with the observation in the interferograms. Velocities 

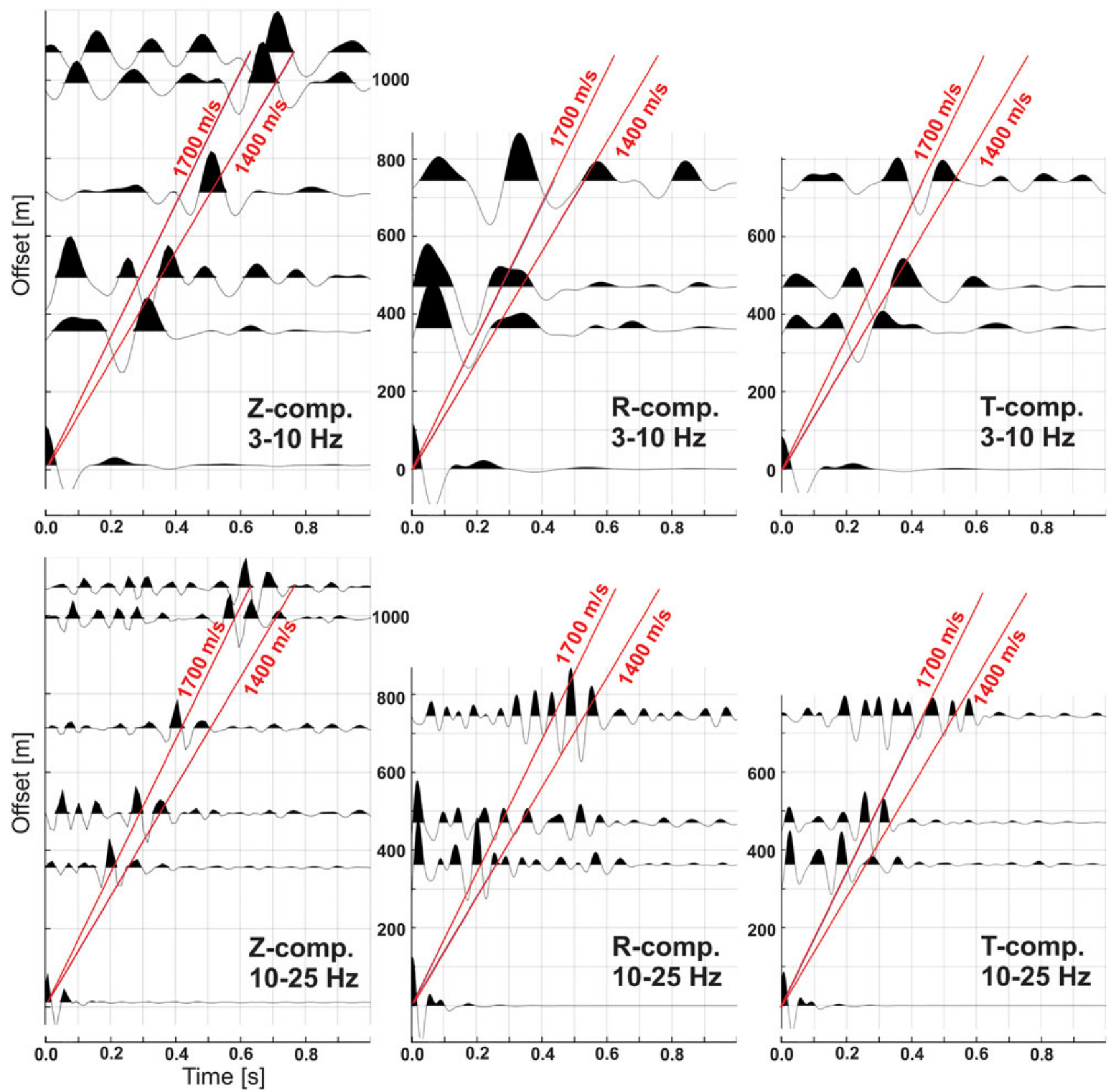

Fig. 8. Interferograms of all receiver pairs (entire monitoring period) in two frequency bands. All individual interferograms have been stacked in $200 \mathrm{~m}$-sized offset bins. Red lines indicate linear move-out for velocities of 1700 and $1400 \mathrm{~m} \mathrm{~s}^{-1}$, respectively.

on the transverse component are generally higher, which qualitatively would agree with the assumption of Love waves. The radial component does not show a clear dispersion image which might result from a low $\mathrm{H} / \mathrm{V}$ ratio. Based on the dispersion characteristics and bandpass filtering of the interferograms (Fig. 7), we qualitatively interpret a velocity inversion with depth as the surface-wave velocities increase with frequency. Tsuji and others (2012) report a similar inverse frequency-velocity relation and associated higher surface-wave modes. They attribute it to a low-velocity layer below the base of the ice, representing unfrozen sediments. We further observe that group velocities in the low-frequency regime (3$10 \mathrm{~Hz}$ ) are higher than the apparent phase velocities obtained from the interferograms. This reverse behaviour can appear if phase velocities increase with frequency $f$, as group velocities $U_{\mathrm{G}}$ and phase velocities $U_{\mathrm{P}}$ are related by Eqn (5) (e.g. Stein and Wyssesion, 2003):

$$
U_{\mathrm{G}}(f)=\frac{U_{\mathrm{P}}(f)}{1-\left.\left(f / U_{\mathrm{P}}(f)\right) \cdot\left(\delta U_{\mathrm{P}} / \delta f\right)\right|_{\mathrm{f}}} .
$$

The investigated area is well covered with GPR profiles which clearly outline the base of the ice and allow for constructing a 3-D ice thickness map (Binder and others, 2013; Fig. 2). It shows that the area comprising the stations APO1, APO2 and APO3 has distinct ice thickness variation, such that inversion of the stacked dispersion curves might not reproduce a useful result. Therefore, we focus on individual station pairs and constrain the ice thickness in the inversion for shear-wave velocity structure based on the GPR data. We further chose to measure and invert surface-wave phase velocity to obtain more accurate shear-wave velocity model, and forward model the synthetic group velocity dispersion (Schwab and Knopoff, 1972) and compare with the measure group velocity image. This two-step approach allows for an independent check of the obtained model based on phase velocity inversion (online Supplementary Fig. S1). Instead of using Eqn 5, we employed a two-station method (Yao and others, 2005, 2006) to measure phase velocity. In order to acquire a reliable dispersion measurement, we applied quality control on the picked dispersion curves by requiring the interstation spacing $(\Delta)$ to be at least two times 

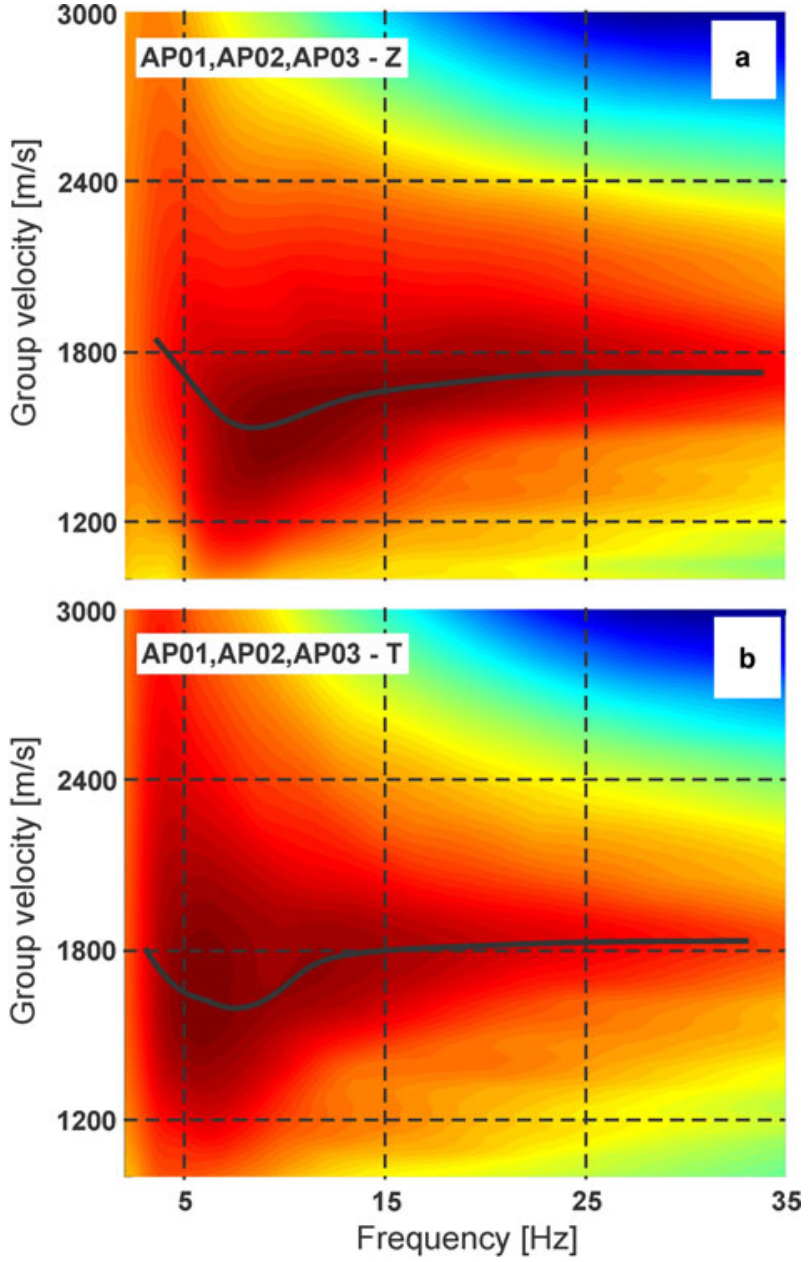

Fig. 9. Dispersion images obtained from stacked frequency-time analysis (FTAN) of the three 3 C stations (AP01, AP02, AP03) for vertical (a) and transverse (b) components, respectively. The solid black line indicates the maximum amplitude in each frequency bin.

the wavelengths $(\lambda): \Delta \geq 2 \lambda$ or $\lambda \leq \Delta / 2$ (Bensen and others, 2007; Luo and others, 2015).

In Figure 10, we show the results for the causal part of the interferogram APO2-APO3. This profile was chosen since the base of the ice is overall flat based on the GPR measurement. Assuming a locally flat bedrock as well, Ning and others (2018) demonstrated that the influence on the dispersion measurement from the one-side dipping surface topography could be ignored, and the obtained shear-wave velocity model will represent an average of the structure along the profile (Luo and others, 2009). We used a non-linear direct search neighbourhood algorithm (Wathelet and others, 2004; Wathelet, 2008), modified after Sambridge (1999) to invert phase velocity dispersion for a three-layer case. We allowed a depth variation of $90-150 \mathrm{~m}$ for the base of layer 1 , and $110-200 \mathrm{~m}$ for the base of layer 2 . The best-fitting model has an ice thickness of $115 \mathrm{~m}$, which compares favourably to GPR data (on average $110 \mathrm{~m}$ along the profile). Below the ice, a thin $(5 \mathrm{~m})$ layer of reduced shear-wave velocity $\left(1550 \mathrm{~m} \mathrm{~s}^{-1}\right)$ is followed by bedrock with a shear-wave velocity of $3000 \mathrm{~m} \mathrm{~s}^{-1}$. The existence of the middle layer is further suggested by inverting for a two-layer model only, in which case the inversion got trapped in a local minimum with significantly poorer data fit and the absence of bedrock velocities (online Supplementary Fig. S2). Likewise, the horizontal components of the non-stacked interferograms had too low $\mathrm{S} / \mathrm{N}$ ratio to allow the generation of a useful dispersion curve.
The thin low-velocity layer possibly represents glacier till and/ or poorly compacted sediments. The occurrence of basal sediments would be not surprising given the abundance elsewhere beneath the Greenland Ice Sheet (Clarke and Echelmeyer, 1996; Bartholomew and others, 2011; Booth and others, 2012; Cowton and others, 2012; Dow and others, 2013; Christianson and others, 2014; Graly and others, 2014; Walter and others, 2014; Mordret and others, 2016; Kulessa and others, 2017). Sub-ice sedimentary layers are reported to have a wide range of shear-wave velocities, from starting as low as $200 \mathrm{~m} \mathrm{~s}^{-1}$ (Nolan and Echelmeyer, 1999) and up to $1500 \mathrm{~m} \mathrm{~s}^{-1}$ (Tsuji and others, 2012), possibly reflecting different degrees of consolidation, composition and saturation.

\subsection{Time-lapse seismic interferometry and the distribution of noise sources}

The continuous recording on all stations offers the possibility for interferometric time-lapse analysis. Interferograms for consecutive $5 \mathrm{~d}$ intervals for all station pairs are calculated using the same processing workflow as outlined in Section 2.2 (Fig. 11). In Figure 11, we show the interferogram pairs with a 'good' signal, which we define as relatively consistent amplitudes at realistic arrival times in at least one of the frequency bands throughout the entire monitoring period. For comparison, interferogram pairs with weak temporal coherence are shown in the online Supplementary Figure S3. In general, high seismic activity (e.g. occurrence of many events) during the syn-discharge period correlates with higher interferogram amplitudes, suggesting that the events are a contributing source of ambient seismic energy. This corresponds to the findings of Preiswerk and Walter (2018) who identify flowing water and icequakes as contributions to mountain glacier ambient noise. In their study, they also monitor an ice-dammed lake with seismic interferometry and observe a strong disturbance of the interferograms during a 1-week long discharge period of the lake.

We use the causal and non-causal characteristics of the interferogram gathers for a qualitative analysis of the dominant ambient noise sources. Of the ten station pairs, three (APO1-APO5, APO2-APO5, APO3-APO5) show relatively consistent amplitudes of the main surface-wave phases throughout the entire monitoring period. Therefore, we interpret the contributing ambient noise sources of these three station pairs to be less influenced by the temporal variation of close-by seismicity. The station pairs APO1-APO5 and APO3-APO5 have orientations roughly perpendicular to the local flow direction of the glacier while station pair APO2-APO5 has an oblique orientation relative to the flow direction. The apparent velocities in the frequency band $3-10 \mathrm{~Hz}$ are slow, e.g. in the range $1400-1450 \mathrm{~m} \mathrm{~s}^{-1}$. Station pair AP02AP05 is more consistent in the causal part, indicating sources towards the north. AP03-AP05 is dominated by non-causal arrivals, which implies that the ambient energy is arriving at AP05 first. Assuming the same source region as for APO2-APO5, we suggest that the non-causal arrivals at APO3-AP05 are generated from surface waves being reflected and back-scattered at the southwestern rim of the glacier. Scattering and reflections of surface waves are a known phenomenon in exploration scale and regional seismology (e.g. Stich and Morelli, 2007; Halliday and others, 2010), and with respect to the orientation of APO3-AP05, the southwestern glacier bed rim is favourably oriented to constitute a secondary stationary-phase source for primary energy originating in the north. Station pair AP01-AP05 has both causal and non-causal arrivals, but with lower velocities compared to the two other station pairs. A possible explanation is the small offset-to-wavelength ratio which may cause interference of causal and non-causal sidelobes of the correlation function, and as such distort the interferogram. In the frequency 

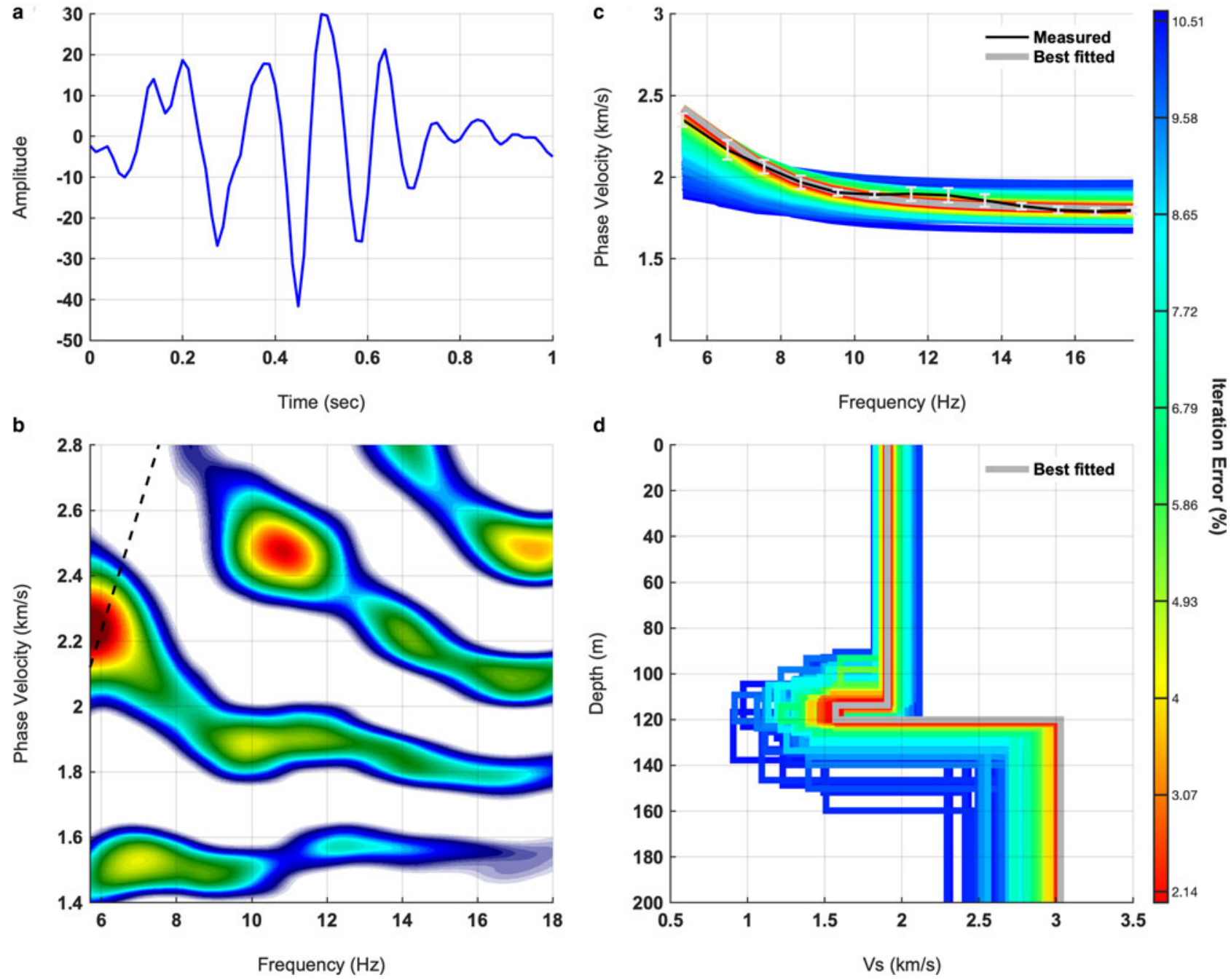

Fig. 10. (a) Causal part of the interferogram AP02-AP03 (vertical component, data from the entire monitoring period). (b) Phase velocity dispersion of (a). (c) Measured and inverted phase velocity dispersion curves. Colours are representing the data misfit expressed as relative RMS error. (d) Shear-wave velocity models for the dispersion curves shown in (c). The grey curve is the chosen model with the smallest RMS error.

band $10-25 \mathrm{~Hz}$, higher velocities $\left(\sim 1700 \mathrm{~m} \mathrm{~s}^{-1}\right)$ are observed on all three station pairs. The temporal variation of the main phases in the interferograms is discussed in more detail below. Phase velocities of interferogram pairs with low temporal consistency (Fig. 9) are partly similar, but those phases cannot be identified during the entire monitoring period. The only robust insight from these station pairs is evidence for high-frequency noise sources towards the northwest during the syn-discharge period. The earlier arrivals at these pairs point towards non-stationary sources in the sector between North and East.

A time-variable distribution of noise sources will change the interferograms. The surge in seismic activity during the syndischarge period does not change the average spatial distribution of the located events. This maybe explains why the ballistic part of the EGF appears stable. The ballistic part of a wave describes the first arrival of a specific phase, while the coda part refers to the later arrivals caused by scattering of the same phase. Arrivals prior to the ballistic part indicate contributions from nonstationary sources, and indeed they are much more pronounced in the syn-discharge period. In order to analyse the contribution from such non-stationary sources, we take advantage of the event detection results. We define $2 \mathrm{~s}$ long time windows around the origin time of the detected events and mute all pre-processed data within these time windows prior to the interferometry. We compare the result with the non-muted dataset and find that there is virtually no difference in the time-lapse gathers in the frequency range of interest $(3-25 \mathrm{~Hz})$. On the other hand, the lack of significant coda waves possibly points towards the absence of consistent scatters at an appropriate length scale.

We therefore use the ballistic part of the EGF close to the expected arrival time as a proxy to an apparent velocity of the surface waves at the station pairs APO1-APO5, AP02-APO5 and APO3-APO5 (Fig. 12). Depending on which part is the most consistent throughout the entire monitoring period, we chose either the causal or acausal section and the frequency band, accordingly. By knowing the offset between the stations, we convert the time axis to apparent velocity and pick velocities at the maximum amplitude close to the expected surface-wave arrivals. For each section, the average apparent velocity is calculated from the mean of all velocity picks, and the apparent velocity variation represents the relative change to the average apparent velocity (Fig. 13). Figure 12 also includes a time-lapse azimuth analysis plot based on the methodology described in Section 2.1.3, where bright spots correlate to large histogram values corresponding to azimuths where most energy is emanating from. Red dots mark the maximum histogram value in each time window. Prior to the jökulhlaup, the dominant noise direction peaks at an azimuth of $\sim 200^{\circ}$ and $40^{\circ}$ relative to the local glacier flow direction. Starting with mid of June, these peaks undergo a smooth transition to higher and lower azimuths, respectively. This transition 

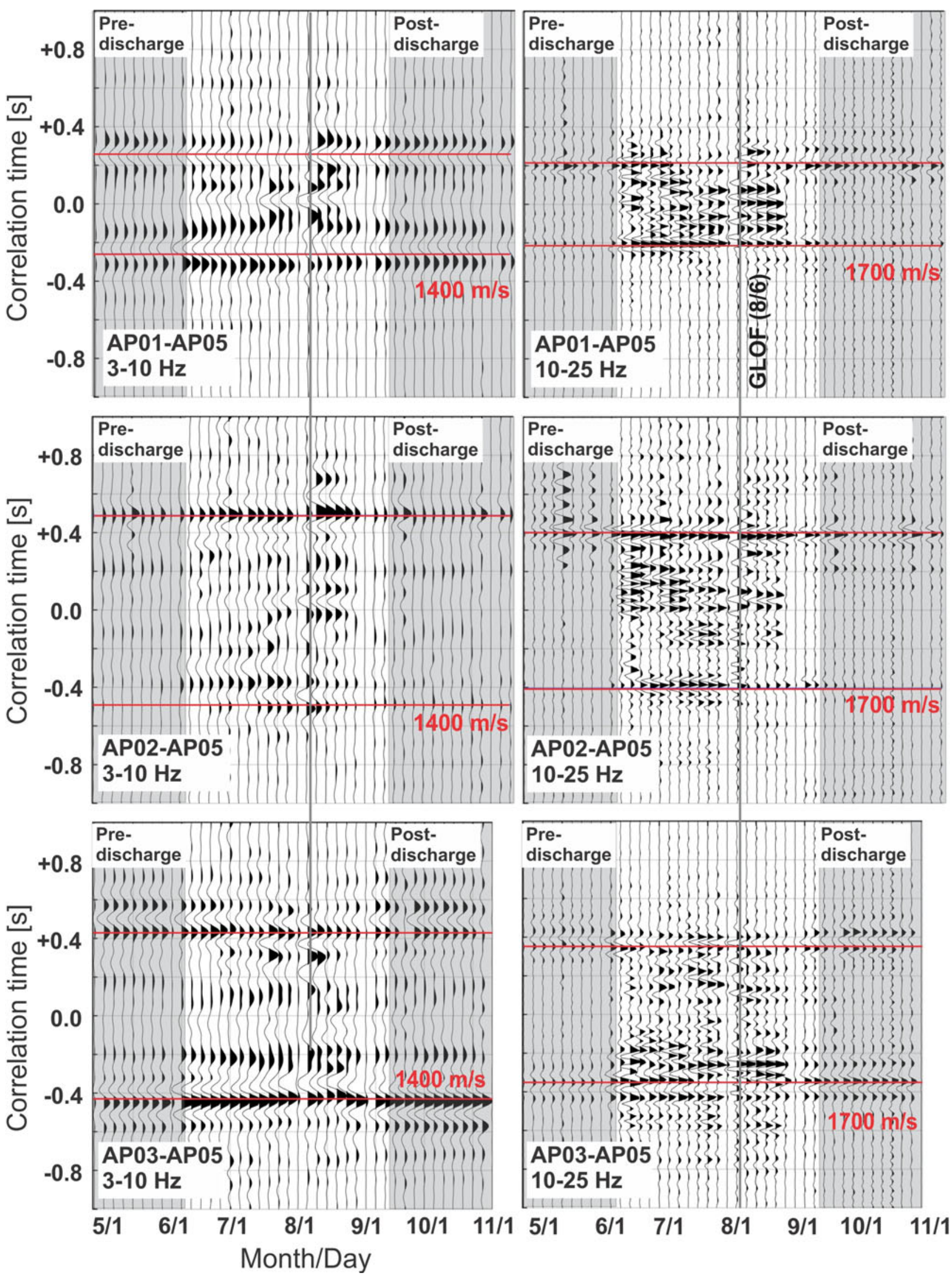

Fig. 11. Time-lapse interferogram sections for the station pairs AP01-AP05, AP02-AP05 and AP03-AP05 in two different frequency bands. Traces are scaled to the maximum amplitude within each section. Red lines: move-out velocities of 1400 and $1700 \mathrm{~m} \mathrm{~s}^{-1}$, respectively. Vertical grey line indicates the occurrence of the jökulhlaup at 8/6/2012. Pre- and post-discharge periods correspond to measured discharge rates $<1.75 \mathrm{~m}^{3} \mathrm{~s}^{-1}$. See text for details.

correlates with the increase in apparent velocity at station pairs APO2-APO5 and APO3-APO5, suggesting that the change in apparent velocity could be a function of the variation of the noise source distribution. With the onset of the jökulhlaup, the dominant noise direction becomes much more distinct and changes to $\sim 260^{\circ}$ for the duration of $\sim 2$ weeks (see also Fig. 5 ). 

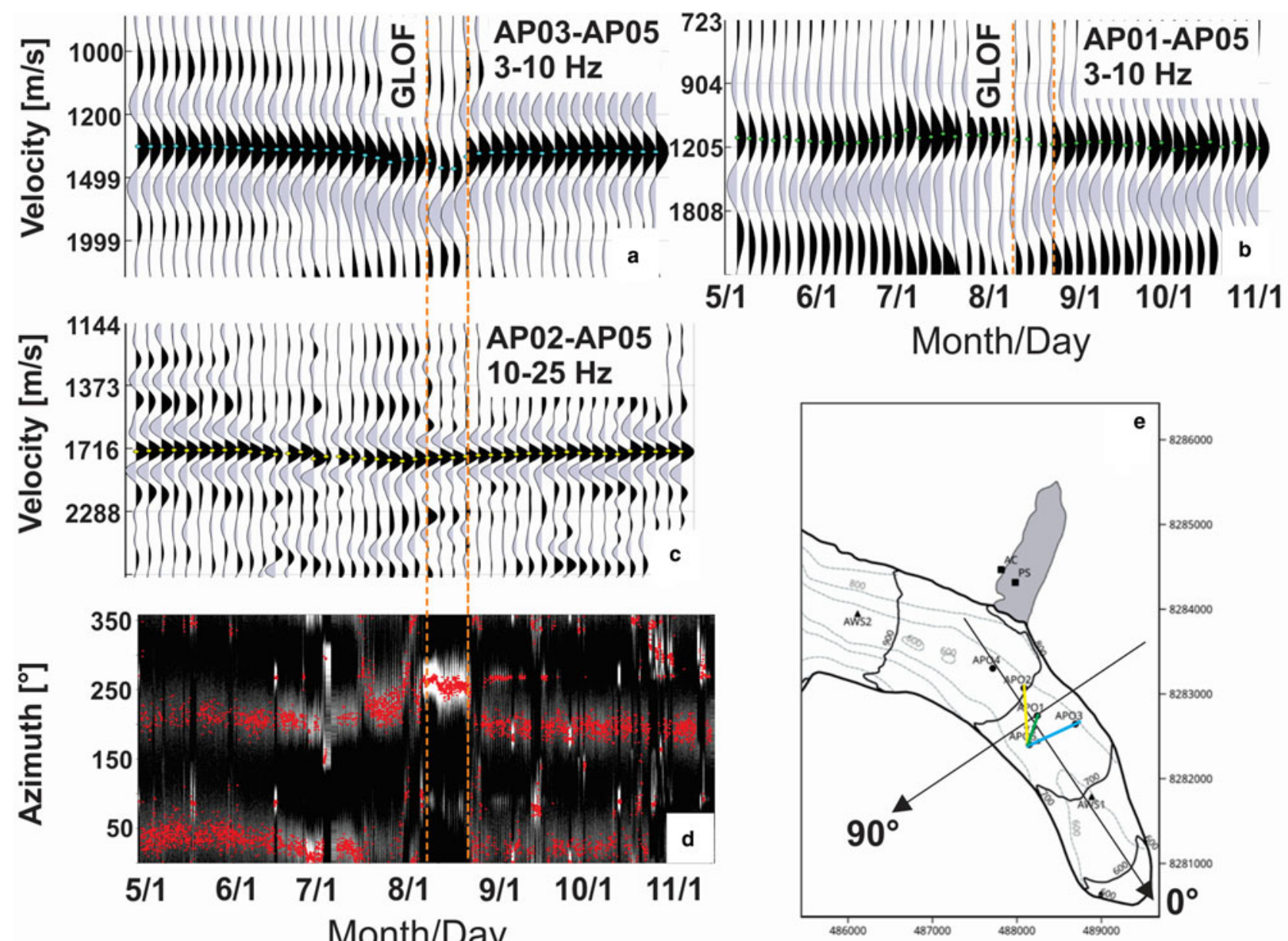

Fig. 12. Zoomed images of selected time-lapse interferogram sections shown in Figures 10(a-c). Traces are individually scaled. The vertical time axis is converted to apparent velocity $\left(\mathrm{m} \mathrm{s}^{-1}\right)$. Non-causal sections have been time-reversed, upwards is the direction of progressing time. Vertical time extent of all sections is $0.4 \mathrm{~s}$. Small circles represent the automatically picked maximum amplitude of the phase. (d) Time-lapse polarization analysis for station APO1 (cf. Fig. 4), where brighter colours indicate larger histogram counts. The azimuth refers to the local glacier flow direction. (e) Black arrows: local coordinate system aligned to the glacier flow direction (azimuth $0^{\circ}$ ). Light blue and yellow arrows: orientation of station pairs APO3-APO5 and APO2-APO5.

If this direction would be considered as the only source of ambient noise for interferometry, then the apparent velocity at the pair APO2-APO5 would increase by $75 \%$ compared to the true medium velocity for the assumption of a plane wave, and by an even larger amount for a close source. While the sudden change indicated in the polarization analysis 2 weeks after the jökulhlaup correlates with a bounce-back of the apparent velocities at APO3-AP05, it is not represented in the smooth time-lapse variation of AP02-AP05. There is an apparent correlation of the polarization maxima $\sim 50^{\circ}$ with $\mathrm{APO} 2-\mathrm{APO} 5$, but it is noted that this interferogram section represents the causal part. Given the orientation of APO2-APO5, the causal part will be dominated by the polarization maxima $\sim 200^{\circ}$. This indicates that a change of the medium velocity might still be considered as a potential contributing factor to the apparent velocity increase.

For both station pairs APO2-APO5 and APO3-APO5, we observe a gradual increase of the apparent high-frequency and low-frequency velocities, respectively. The onset of the gradual velocity increase coincides with the first period of positive temperatures in late May (Fig. 13). Throughout the pre-jökulhlaup melt season, both station pairs experience a velocity increase coinciding with prominent melting and consequently, discharge events. Station pair APO2-APO5 shows a velocity increase of $\sim 2 \%$ within a week during the first prominent melt event at the end of June. Starting with the second prominent melt event in the middle of July, the station pair APO3-APO5 exhibits a velocity increase of $\sim 4 \%$ within 2 weeks. The last week before the actual jökulhlaup, we observe a velocity decrease for both station pairs. However, whereas station pair APO2-APO5 shows a continued velocity decrease after the jökulhlaup, station pair APO3-APO5 shows another significant velocity increase in the $10 \mathrm{~d}$ following the jökulhlaup, before a sudden bounce-back to lower velocities can be observed. Despite an apparent relation between these short-term velocity variations and dominant melt events, we refrain from an interpretation due to the partial correlation with the noise source distribution as discussed above.

Denser station coverage would be required to gain more confidence in the apparent short-term velocity variations, and to conclusively rule out changes of the first-arrival wavelet caused by episodic (days to few weeks) contributions of non-stationary sources. On the opposite, the mean long-term velocity trends of these two station pairs (e.g. velocity increase prior to the jökulhlaup and decrease afterwards) are similar in magnitude. The two station pairs have an azimuth difference of $70^{\circ}$, such that a long-term change of the ambient noise source distribution would likely result in different magnitudes of apparent velocity variations. Furthermore, the temporal spectral variation of raw data and the interferogram pairs does not show a clear correlation with the gradual increase of apparent velocity (online Supplementary Fig. S4). Except for a 2-week period at the end of June, the spectrograms do not indicate the emergence of a different type of noise source but appear to be scaled according to the seismicity rate. This absence of pronounced spectral variation in the seismic ambient noise sources is another indication that 


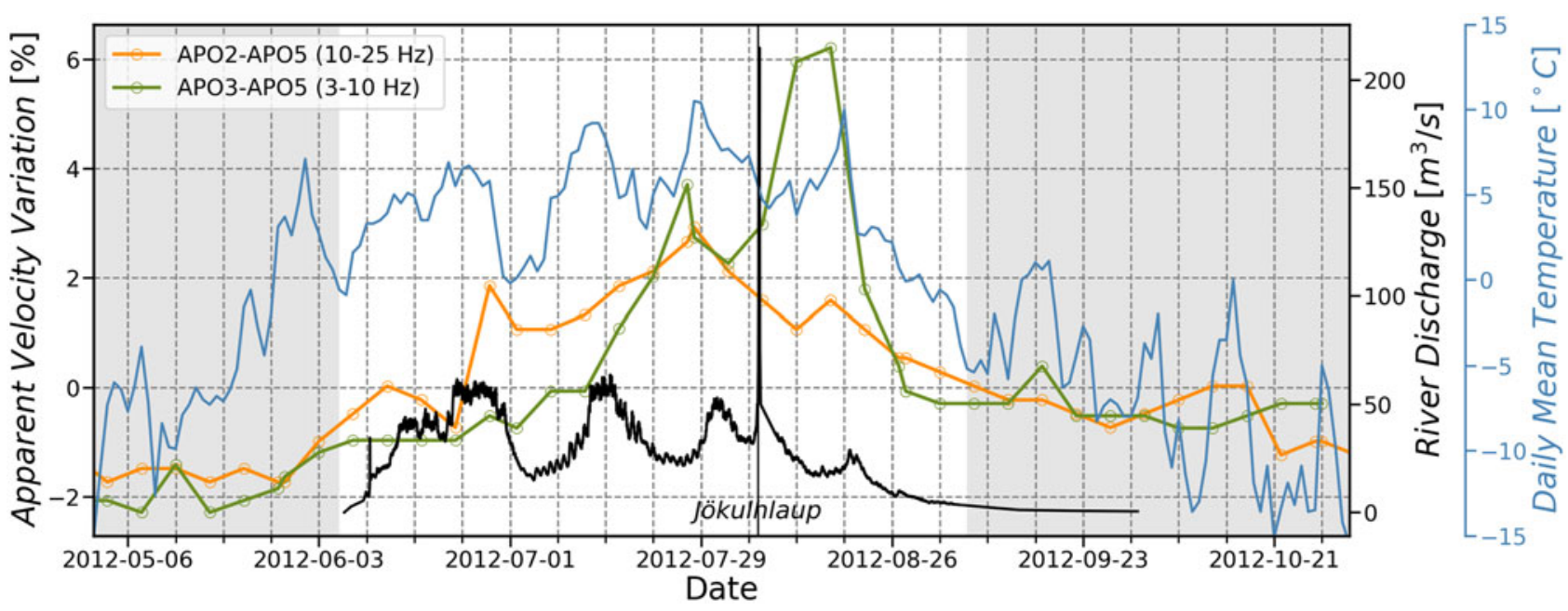

Fig. 13. Time series of the relative velocity variations for station pairs APO2-APO5 (orange line) and APO3-APO5 (green line). Additionally, river discharge (black line) and air temperature (blue line) are shown.

changes in the medium over time are potentially contributing to the observed apparent velocity changes.

APO1-APO5 is more challenging to interpret, as the strong non-causal arrival is split into two phases with opposing time-lapse variation. The phase with an average velocity of $\sim 1160 \mathrm{~m} \mathrm{~s}^{-1}$ seems to show an opposite behaviour (e.g. a syndischarge velocity increase), but this phase velocity is significantly lower than established from other interferogram sections. Furthermore, the velocity variation fluctuates strongly over time. Station pair APO1-APO5 has a small offset in relation to the seismic wavelength under consideration, implying that the velocity estimation in this frequency band might be significantly flawed. This area is also characterized by basal crevassing as seen in GPR data (Binder and others, 2012), thus introducing further effects on the propagation of low-frequency surface waves. Given the sparseness of our station network and the short offset of this station pair, we conclude that further measurements would be required to resolve that particular velocity ambiguity.

The apparent velocity is a function of the arrival time and the offset between two stations. Glacier dynamics potentially introduce a continuous change of distance between surface points situated several hundred meters apart. Consequently, the offset between the stations will vary over time and potentially contribute to changes in apparent velocities over time. All seismic stations were equipped with continuous single-frequency GPS receivers, although the instruments on AP01 and APO5 failed. A GPS station installed on solid rock in the glacier fore-field served as a local reference station for the differential processing. Daily static solutions were calculated using the Bernese GPS Software version 5.0 (Dach and others, 2007). The displacement history of the three remaining stations shows identical patterns, but with different magnitudes. During the syn-discharge period, the stations AP02 and AP04 moved in total $2 \mathrm{~m}$ towards each other. The same accounts for the station pair APO3-AP04, while station AP03 did not change relative to APO2. To explain a velocity increase of $4 \%$ on the station pair AP03-AP05 by a change of the offset only, the stations would need to move towards each other by $24 \mathrm{~m}$. Additionally, the sudden bounce-back of velocities at the end of August is not reflected in the cumulated displacement curve which shows a gradual increase. We therefore think it is unlikely that glacier dynamics contribute significantly to the observed variation of apparent velocity, although we are lacking displacement data of station APO5 to quantify its effect on the time-lapse interferograms in Figure 12.

\subsection{Discussion of the observed apparent velocity variation}

In the previous section, we concluded that both the spatiotemporal variation of the ambient noise sources as well as medium changes can potentially contribute to the observed variation of the apparent velocity and analysed the noise source distribution in detail. Here we discuss which possible medium changes could influence the observed apparent velocity variation on the station pairs APO3-APO5 $(3-10 \mathrm{~Hz})$ and APO2-APO5 (10-25 Hz).

Surface-wave phase velocity is mainly sensitive to shear-wave velocity (Xia and others, 1999). The sensitivity kernel (online Supplementary Fig. S5) for the obtained shear-wave velocity model (Fig. 10d) shows that the low-frequency band $(<10 \mathrm{~Hz})$ is mostly sensitive to changes in the sediment layer or to changes at the base of the ice. Gradual increase of water saturation in the sediment layer would lead to an increase of bulk density and therefore to a decrease in shear-wave velocity (Biot, 1956a, 1956b; Dvorkin and others, 1999). This contrasts with the assumption of steadily increasing water influx in the pre-jökulhlaup phase. The opening of basal crevasses would also lead to a decrease in bulk velocity, although a recent study (Zhan, 2019) illustrated the complications introduced by a structural anisotropy effect of the basal crevasses. We therefore conclude that the velocity changes in the low-frequency regime do not reflect changes in the sediment layer.

The station pair APO2-APO5 $(10-25 \mathrm{~Hz})$ reflects shear-wave velocity changes in the upper $20-70 \mathrm{~m}$ of the ice body. P- and $\mathrm{S}$-wave velocities of a solid-state body increase with effective stress, which is coupled to an increase of the confining pressure (e.g. Knight and Endres, 2005). Effective stress is the difference between confining pressure and pore pressure (Terzaghi, 1936), and its increase leads to closure of cracks and voids. Nolan and Echelmeyer (1999) used time-lapse active seismic to monitor changes of seismic reflection coefficients during a jökulhlaup on Black Rapids Glacier in Alaska. In terms of spatial extent and temporal development of the jökulhlaup, their study site is comparable to the Southeast Outlet Glacier. They observed transient short-term (e.g. daily) variations of the reflection signature after sudden lake discharges and attribute these to increase in effective stress and a decrease in saturation of a subglacial sediment layer. Spatiotemporal changes of both vertical and horizontal confining stress can be caused by local basal water pressure fluctuations and consequently, spatiotemporally varying basal sliding rates. Both effects are likely throughout the subglacial drainage system 
evolution in the pre-jökulhlaup period, as also shown by differential GPS displacement rates (Section 3.5).

The subglacial propagation of the front of rapidly-rising jökulhlaups has been explained with a highly pressurized subglacial sheet flow (Jóhannesson, 2002; Flowers and others, 2004; Björnsson, 2011). This sheet flow represents a single event in time which converts the highly pressurized and inefficient basal drainage system into a well-connected drainage system with high flow rates due to channelization of the subglacial water flow (Röthlisberger, 1972). Channelized drainage systems favour the formation of an arterial network with few main channels at low water pressures, routing the basal water through the glacier in an efficient way (Schoof, 2010). A hydrological gradient is introduced through the connection of an inefficient and pressurized drainage system with an efficient drainage system. This gradient drives basal water flow from the inefficient drainage system to the channelized system and minimizes basal water pressure difference. Minimization of the basal water pressure difference equalizes basal sliding rates and restores the system to the premelt season confining stress state. Accordingly, one might want to correlate the observed apparent velocity changes in the ice with a localized increase in both vertical and horizontal confining stress during the pre-jökulhlaup pressure build-up phase and return to the homogeneous stress state during the postjökulhlaup phase. This, however, contrasts with the interpretation of increased surface crevassing which is likely to result in a bulk velocity decrease throughout the entire period. However, we have no quantitative estimate of the depth extent of the crevasses to infer their actual impact on the bulk velocity.

Velocity anisotropy due to the ice fabric is another factor to be accounted for in glacial ice (Vélez and others, 2016; Hofstede and others, 2018) and can be related to the local stress regime. Based on reflection seismic data, Diez and others (2014) report P-wave stacking velocity anisotropy of $7 \%$ and $\mathrm{SH}$-wave stacking velocity anisotropy of $1 \%$ for a glacier in the Swiss Alps. A recent study based on shear-wave splitting (Smith and others, 2017) found S-wave velocity anisotropy up to $5 \%$ in a fast-moving Antarctic ice sheet. This anisotropy is explained with a specific ice fabric which develops in a stress/strain regime characterized by alongflow extension and cross-flow confinement. While it is assumed that increase of confining stress can lead to coeval re-orientation of the ice crystals and thus to a change in fabric, the reduction of confining stress will not be reflected immediately in the fabric. Due to the 'memory' effect of ice, the previously imprinted high-stress fabric is likely to remain for several years at least (Schulson and Duval, 2009). Therefore, the velocity decrease at APO2-APO5 in the post-jökulhlaup phase cannot be reconciled with fabric anisotropy either.

In conclusion, we cannot find a singular explanation for the apparent velocity variations which is in agreement with the interpretation of increased seismicity due to surface crevassing. While changes in the ambient noise sources can potentially explain these variations, we also do not find a clear and consistent correlation with different proxies for the ambient noise source distribution (polarization analysis, spectrograms) for all station pairs. As our discussion shows, many different processes potentially contribute to the in situ medium velocity and the observations likely represent their net effect as well. At this stage, we therefore conclude that our interferometric time-lapse analysis remains ambiguous, also partly due to the sparse station geometry. A properly designed interferometric observation network would be required to obtain more robust results. A denser station coverage would also invite the application of recent methodological advancements in seismic interferometry which aim at minimizing the influence of directional bias in the ambient noise source distribution (Lindner and others, 2018).

\section{Conclusions}

For the first time, we have documented a rapidly-rising jökulhlaup fill-and-drain cycle with 'on-ice' passive seismic monitoring in its source zone. In total, our dataset covers a continuous 6-month period. We show that seismic activity is correlated with transient water input due to precipitation, snow and ice melt. The vast majority of the seismic events are interpreted to be caused by surface crevassing, which points towards basal drainage as opposed to englacial channelling. Based on GPR-constrained interferometric dispersion inversion, we interpret a thin lowvelocity sediment layer in between the ice body and the bedrock, adding to the rapidly growing body of evidence for the presence of sediment beneath the Greenland Ice Sheet.

We further show the potential of time-lapse seismic interferometry to monitor velocity changes inferred from the ballistic part of the surface wave. Our interferometric study indicates that raypaths of ambient seismic energy in a narrow outlet glacier bed appear to be complex and are possibly subjected to reflection and large-scale scattering. We find a correlation of apparent velocity changes with air temperatures, seismicity rate and river discharge.

While spectrograms do not indicate the emergence of a different type of noise source during the 6 months, time-lapse azimuthal polarization analysis suggests that the distribution of the prevailing ambient noise sources vary over the deployment period. This likely contributes to the observed temporal changes in arrival times on some station pairs and renders a process-based interpretation of apparent velocity changes ambiguously. For example, the observed apparent velocity variation throughout the melting season might be indicative of a jökulhlaup-triggered switch between an inefficient, distributed basal drainage system to a channelized system with higher drainage capacity. However, the observation of increased surface crevassing is challenging this interpretation. Future fieldwork and research should therefore aim at seismic monitoring and interferometric imaging with increased temporal, vertical and lateral resolution, and be combined with denser GPS sampling as well. Such data could then be verified against hydrological and geomechanical models of processes potentially occurring during a rapidly-rising jökulhlaup.

Supplementary material. The supplementary material for this article can be found at https://doi.org/10.1017/jog.2020.9.

Acknowledgements. The passive seismic monitoring was possible due to a SeisUK loan (http://www.le.ac.uk/seis-uk) and the gathered seismic dataset is accessible through the SeisUK data archive. The EU FP7 Interact and the Polarvision project (Austrian Federal Ministry of Science and Research, GZ: 37.556/0002-II/4/2010) funded the travel and accommodation costs for the 2012 field team (Mertl S., Weyss G., Binder D.). Seismic sensors were produced by Geosono (www.geosono.com) and provided by the Vienna Technical University (em. Prof. Brückl E.). Complementary data were provided by the Greenland Ecosystem Monitoring Programme (www.g-e-m.dk). Fischer A. (Innsbruck University) and the Stubaier Gletscherbahnen (A) helped out with the geotextile organization and provision. Installation of the monitoring network would have been not possible without the great support of the Zackenberg Research Station logistics. JIW was supported by the National Science Foundation Office of Polar Programs Award 1745135. Phase velocity inversion was done with the Geopsy software (http://www.geopsy.org, last accessed January 2019). We thank Fabian Walter and three anonymous reviewers for their detailed and very helpful comments.

\section{References}

Albon S, Thiede J and Holmén K (2014) Greenland Ecosystem Monitoring. GEM Evaluation. Final Report, 70 pp. Danish Energy Agency.

Allstadt K and Malone SD (2014) Swarms of repeating stick-slip icequakes triggered by snow loading at Mount Rainier volcano. Journal of 
Geophysical Research: Earth Surface 119(5), 1180-1203. doi: 10.1002/ 2014JF003086.

Anderson RS and 6 others (2004) Strong feedbacks between hydrology and sliding of a small alpine glacier. Journal of Geophysical Research: Earth Surface 109(F3), F03005. doi: 10.1029/2004JF000120.

Aster RC and Winberry JP (2017) Glacial seismology. Reports on Progress in Physics 80(12), 126801. doi: 10.1088/1361-6633/aa8473.

Baillard C, Crawford WC, Ballu V, Hibert C and Mangeney A (2014) An automatic kurtosis-based $P$ - and S-phase picker designed for local seismic networks. Bulletin of the Seismological Society of America 104 (1), 394 409. doi: 10.1785/0120120347.

Bakulin A and Calvert R (2006) The virtual source method: theory and case study. Geophysics 71(4), SI139-SI150. doi: 10.1190/1.2216190.

Bartholomaus TC and 5 others (2015) Subglacial discharge at tidewater glaciers revealed by seismic tremor. Geophysical Research Letters 42(15), 63916398.

Bartholomaus TC, Anderson RS and Anderson SP (2008) Response of glacier basal motion to transient water storage. Nature Geoscience 1, 33-37. doi: 10.1038/ngeo.2007.52.

Bartholomew I and 6 others (2011) Supraglacial forcing of subglacial drainage in the ablation zone of the Greenland ice sheet. Geophysical Research Letters 38(8), L08502. doi: 10.1029/2011GL047063.

Behm M (2017) Feasibility of borehole ambient noise interferometry for permanent reservoir monitoring. Geophysical Prospecting 65(2), 563-580. doi 10.1111/1365-2478.12424.

Behm M, Leahy GM and Snieder R (2014) Retrieval of local surface wave velocities from traffic noise - an example from the La Barge basin (Wyoming). Geophysical Prospecting 62(2), 223-243. doi: 10.1111/ 1365-2478.12080.

Benn D, Gulley J, Luckman A, Adamek A and Glowacki P (2009) Englacial drainage systems formed by hydrologically driven crevasse propagation. Journal of Glaciology 55(191), 513-523. doi: 10.3189/002214309788816669.

Bensen GD and 7 others (2007) Processing seismic ambient noise data to obtain reliable broad-band surface wave dispersion measurements. Geophysical Journal International 169(3), 1239-1260. doi: 10.1111/j. 1365-246X.2007.03374.x

Binder D and 5 others (2012) Potential storage mechanism during a glacial lake outburst. Presentation at the IGS Conference 'The Geophysics of the Cryosphere', 9-10 February 2012, London, United Kingdom.

Binder D and 5 others (2013) A.P. Olsen Ice Cap - ice thickness, dynamics and mass balance. Presentation at the IASC Workshop on the dynamics and mass budget of Arctic glaciers, 26-28 February 2013, Obergurgl Austria.

Biot MA (1956a) Theory of propagation of elastic waves in a fluid-saturated porous solid. I. Low-frequency range. Journal of the Acoustical Society of America 28(2), 168-178. doi: 10.1121/1.1908239.

Biot MA (1956b) Theory of propagation of elastic waves in a fluid-saturated porous solid. II. Higher frequency range. Journal of the Acoustical Society of America 28(2), 179-191.

Björnsson H (2011) Understanding jökulhlaups: from tale to theory. Journal of Glaciology, 56(200), 1002-1010. doi: 10.3189/002214311796406086.

Boon S and Sharp M (2003) The role of hydrologically-driven ice fracture in drainage evolution on an Arctic glacier. Geophysical Research Letters 30(18), 1916. doi: 10.1029/2003GL018034.

Booth AD and 6 others (2012) Thin-layer effects in glaciological seismic amplitude-versus-angle (AVA) analysis: implications for characterising a subglacial till unit, Russell Glacier, West Greenland. The Cryosphere 6(4) 909-922. doi: 10.5194/tc-6-909-2012.

Brueckl E, Binder D and Mertl S (2015) Seismic sources from landslides and glaciers. In Beer M, Kougioumtzoglou I, Patelli E and Au IK (eds), Encyclopedia of Earthquake Engineering. Berlin, Heidelberg: Springer, pp. 1-34. doi: 10.1007/978-3-642-36197-5-385-1.

Carmichael JD and 6 others (2015) Seismicity on the western Greenland Ice Sheet: surface fracture in the vicinity of active moulins. Journal of Geophysical Research: Earth Surface 120(6), 1082-1106. doi: 10.1002/ 2014JF003398

Carrivick JL and 11 others (2017) Ice-dammed lake drainage evolution at Russell Glacier, West Greenland. Frontiers in Earth Science 5, 100. doi: 10.3389/feart.2017.00100.

Cheng F, Xia J, Behm M, Hu Y and Pang J (2019) Automated data selection in the Tau-p domain: application to passive surface wave imaging. Surveys in Geophysics 40(5), 1211-1228. doi: 10.1007/s10712-019-09530-2.
Cheng F, Xia J, Xu Z, Hu Y and Mi B. (2018) Frequency-wavenumber (FK)-based data selection in high-frequency passive surface wave survey. Surveys in Geophysics 39(4), 661-682. doi: 10.1007/s10712-018-9473-3.

Christianson $\mathrm{K}$ and 7 others (2014) Dilatant till facilitates ice-stream flow in northeast Greenland. Earth and Planetary Science Letters 401, 57-69. doi: 10.1016/j.epsl.2014.05.060.

Clarke GKC (1982) Glacier outburst floods from 'Hazard Lake', Yukon Territory, and the problem of flood magnitude prediction. Journal of Glaciology 28(98), 3-21. doi: 10.3189/S0022143000011746.

Clarke T and Echelmeyer K (1996) Seismic-reflection evidence for a deep subglacial trough beneath Jakobshavns Isbræ, West Greenland. Journal of Glaciology 42(141), 219-232. doi: 10.3189/S0022143000004081.

Cowton T, Nienow P, Bartholomew I, Sole A and Mair D (2012) Rapid erosion beneath the Greenland ice sheet. Geology 40(4), 343-346. doi: 10.1130/ G32687.1.

Dach R, Hugentobler U, Fridez P and Meindl M (2007) Bernese GPS Software Version 5.0. Astronomical Institute, University of Bern.

Das SB and 6 others (2008) Fracture propagation to the base of the Greenland Ice Sheet during supraglacial lake drainage. Science 320(5877), 778-781. doi: $10.1126 /$ science.1153360.

Deichmann N and 5 others (2000) Evidence for deep icequakes in an Alpine glacier. Annals of Glaciology 31, 85-90. doi: 10.3189/172756400781820462.

Deichmann N, Ansorge J and Röthlisberger H (1979) Observations of glacier seismicity on Unteraargletscher. Journal of Glaciology 23(89), 409. doi: 10. 3189/S0022143000030069.

Diez A and 7 others (2014) Influence of ice crystal anisotropy on seismic velocity analysis. Annals of Glaciology 55(67), 97-106. doi: 10.3189/ 2014AoG67A002.

Dow CF and 5 others (2013) Seismic evidence of mechanically weak sediments underlying Russell Glacier, West Greenland. Annals of Glaciology 54(64), 135-141. doi: 10.3189/2013AoG64A032.

Dow CF and 10 others (2015) Modeling of subglacial hydrological development following rapid supraglacial lake drainage. Journal of Geophysical Research: Earth Surface 120(6), 1127-1147. doi: 10.1002/2014JF003333.

Doyle SH and 9 others (2013) Ice tectonic deformation during the rapid in situ drainage of a supraglacial lake on the Greenland Ice Sheet. The Cryosphere 7(1), 129-140. doi: 10.5194/tc-7-129-2013.

Draganov D, Campman X, Thorbecke J, Verdel A and Wapenaar K (2009) Reflection images from ambient seismic noise. Geophysics 74(5), A63-A67. doi: $10.1190 / 1.3193529$.

Dvorkin J, Prasad M, Sakai A and Lavoie D (1999) Elasticity of marine sediments: rock physics modeling. Geophysical Research Letters 26(12), 17811784. doi: 10.1029/1999GL900332.

Einarsson B and 5 others (2016) A spectrum of jökulhlaup dynamics revealed by GPS measurements of glacier surface motion. Annals of Glaciology 57(72), 47-61. doi: 10.1017/aog.2016.8.

Einarsson B, Jóhannesson T, Thorsteinsson T, Gaidos E and Zwinger T (2017) Subglacial flood path development during a rapidly-rising jökulhlaup from the western Skafta cauldron, Vatnajökull, Iceland. Journal of Glaciology 63(240), 670-682. doi: 10.1017/jog.2017.33.

Fichtner A (2014) Source and processing effects on noise correlations. Geophysical Journal International 197(3), 1527-1531. doi: 10.1093/gji/ ggu093.

Flowers GE, Björnsson H, Palsson F and Clarke GKC (2004) A coupled sheet-conduit mechanism for jökulhlaup propagation. Geophysical Research Letters 31, L05401. doi: 10.1029/2003GL019088.

Forghani F and Snieder R (2010) Underestimation of body waves and feasibility of surface-wave reconstruction by seismic interferometry. The Leading Edge 29(7), 790-794. doi: 10.1190/1.3462779.

Fountain AG, Jacobel RW, Schlichting R and Jansson P (2005) Fractures as the main pathways of water flow in temperate glaciers. Nature 433(7026), 618-620. doi: 10.1038/nature03296.

Froment B and 5 others (2010) Estimation of the effect of nonisotropically distributed energy on the apparent arrival time in correlations. Geophysics 75(5), SA85-SA93. doi: 10.1190/1.3483102.

Fudge TJ, Harper JT, Humphrey NF and Pfeffer WT (2009) Rapid glacier sliding, reverse ice motion and subglacial water pressure during an autumn rainstorm. Annals of Glaciology 50(52), 101-108. doi: 10.3189/ 172756409789624247.

Galetti E and Curtis A (2012) Generalised receiver functions and seismic interferometry. Tectonophysics 532-535, 1-26. doi: 10.1016/j.tecto.2011. 12.004 
Geiger L (1912) Probability method for the determination of earthquake epicenters from the arrival time only. Bulletin of St. Louis University 8, 60-71.

Graly JA, Humphrey NF, Landowski CM and Harper JT (2014) Chemical weathering under the Greenland Ice Sheet. Geology 42(6), 551-554. doi: $10.1130 / \mathrm{G} 35370.1$.

Grinsted A, Hvidberg CS, Campos N and Dahl-Jensen D (2017) Periodic outburst floods from an ice-dammed lake in East Greenland. Scientific Reports 7, 9966. doi: 10.1038/s41598-017-07960-9.

Halliday DF and 6 others (2010) Interferometric ground-roll removal: attenuation of scattered surface waves in single-sensor data. Geophysics, 75(6), SA15-SA25. doi: 10.1190/1.3360948.

Hannemann $\mathbf{K}$ and 5 others (2014) Three-dimensional shallow structure from high-frequency ambient noise tomography: new results for the Mygdonia basin-Euroseistest area, northern Greece. Journal of Geophysical Research: Solid Earth 119(6), 4979-4999. doi: 10.1002/ 2013JB010914.

Harper JT, Bradford JH, Humphrey NF and Meierbachtol TW (2010) Vertical extension of the subglacial drainage system into basal crevasses. Nature 467, 579-582. doi: 10.1038/nature09398.

Heeszel DS, Walter F and Kilb DL (2014) Humming glaciers. Geology 42(12), 1099-1102. doi: 10.1130/G35994.1.

Helmstetter A, Moreau L, Nicolas B, Comon P and Gay M (2015) Intermediate-depth icequakes and harmonic tremor in an Alpine glacier (Glacier d'Argentière, France): evidence for hydraulic fracturing? Journal of Geophysical Research: Earth Surface 120(3), 402-416. doi: 10.1002/ 2014JF003288.

Hillers G and 5 others (2015a) In situ observations of velocity changes in response to tidal deformation from analysis of the high-frequency ambient wavefield. Journal of Geophysical Research: Solid Earth 120(1), 210-225. doi: $10.1002 / 2014$ JB011318.

Hillers G and 5 others (2015b) Noise-based monitoring and imaging of aseismic transient deformation induced by the 2006 Basel reservoir stimulation. Geophysics 80(4), KS51-KS68. doi: 10.1190/geo2014-0455.1.

Hofstede C and 6 others (2018) Physical conditions of fast glacier flow: 2. Variable extent of anisotropic ice and soft basal sediment from seismic reflection data acquired on Store Glacier, west Greenland. Journal of Geophysical Research: Earth Surface 123(2), 349-362. doi: 10.1002/ 2017JF004297.

Iken A and Bindschadler R (1986) Combined measurements of subglacial water pressure and surface velocity of Findelengletscher, Switzerland: conclusions about drainage system and sliding mechanism. Journal of Glaciology 32(10), 101-119. doi: 10.3189/S0022143000006936.

Jensen LM, Christensen TR and Schmidt NM (eds.) (2014) Zackenberg Ecological Research Operations 19th Annual Report, 2013. Aarhus University, DCE - Danish Centre for Environment and Energy. 130 pp.

Jóhannesson T (2002) Propagation of a substantial flood wave during the initiation of a jökulhlaup. Hydrological Sciences Journal 47(3), 417-434. doi: $10.1080 / 02626660209492944$.

Jones GA, Kulessa B, Doyle SH, Dow CF and Hubbard A (2013) An automated approach to the location of icequakes using seismic waveform amplitudes. Annals of Glaciology 54(64), 1-9. doi: 10.3189/2013AoG64A074.

Jurkevics A (1988) Polarization analysis of three-component array data. Bulletin of the Seismological Society of America 78(5), 1725-1743.

Keilis-Borok VI eds. (1989) Seismic Surface Waves in a Laterally Inhomogeneous Earth. Dortrecht, Boston, London: Kluwer.

Knight RJ and Endres AL (2005) An introduction to rock physics principles for near-surface geophysics. In Butler D (ed.), Near Surface Geophysics, Society of Exploration Geophysicists. Tulsa: Society of Exploration Geophysicists, pp. 31-69.

Kulessa B, Hubbard AL, Booth AD, Bougamont M, Dow CF, Doyle SH, Christoffersen P, Lindbäck K, Pettersson R, Fitzpatrick AAW and Jones GA (2017) Seismic evidence for complex sedimentary control of Greenland Ice Sheet flow. Science Advances 3(8), e1603071. doi: 10.1126/ sciadv. 1603071.

Larose E and 11 others (2015) Environmental seismology: What can we learn on earth surface processes with ambient noise? Journal of Applied Geophysics 116, 62-74. doi: 10.1016/j.jappgeo.2015.02.001.

Larsen M and 5 others (2013) A satellite perspective on jökulhlaups in Greenland. Hydrology Research 44(1), 68-77. doi: 10.2166/nh.2012.195.

Larsen SH, Citterio M, Hock R and Ahlström AP (2015) Surface mass balance at A.P. Olsen Ice Cap, NE Greenland. Geophysical Research Abstracts 17, EGU2015-15481.
Lindner F, Weemstra C, Walter F and Hadziioannou C (2018) Towards monitoring the englacial fracture state using virtual-reflector seismology. Geophysical Journal International 214(2), 825-844. doi: 10.1093/gji/ggy156.

Luo $Y$ and 5 others (2015) On the limitations of interstation distances in ambient noise tomography. Geophysical Journal International 201(2), 652-661. doi: 10.1093/gji/ggv043.

Luo Y, Xia J, Liu J, Xu Y and Liu Q (2009) Research on the middleof-receiver-spread assumption of the MASW method. Soil Dynamics and Earthquake Engineering 29(1), 71-79. doi: 10.1016/j.soildyn.2008.01.009.

Mayer C and Schuler TV (2005) Breaching of an ice dam at Qorlortossup tasia, south Greenland. Annals of Glaciology 42, 297-302. doi: 10.3189/ 172756405781812989

Métaxian J, Araujo S, Mora M and Lesage P (2003) Seismicity related to the glacier of Cotopaxi Volcano, Ecuador. Geophysical Research Letters 30(9). doi: 10.1029/2002GL016773.

Mikesell TD and 5 others (2012) Monitoring glacier surface seismicity in time and space using Rayleigh waves. Journal of Geophysical Research: Earth Surface 117(F2), F02020. doi: 10.1029/2011JF002259.

Mordret A, Mikesell TD, Harig C, Lipovsky BP and Prieto GA (2016) Monitoring southwest Greenland's ice sheet melt with ambient seismic noise. Science Advances 2(5), e1501538. doi: 10.1126/sciadv.1501538.

Nakata N, Chang JP, Lawrence JF and Boué P (2015) Body wave extraction and tomography at Long Beach, California, with ambient-noise interferometry. Journal of Geophysical Research: Solid Earth 120(2), 1159-1173. doi: 10.1002/2015JB011870.

Nakata N and Snieder R (2012) Time-lapse change in anisotropy in Japan's near surface after the 2011 Tohoku-Oki earthquake. Geophysical Research Letters 39(11), L11313. doi: 10.1029/2012GL051979.

Neave KG and Savage JC (1970) Icequakes on the Athabasca glacier. Journal of Geophysical Research 75(8), 1351-1362. doi: 10.1029/JB075i008p01351.

Ning L, Da T, Wang L, Yuan S and Pang J (2018) Numerical investigation of Rayleigh-wave propagation on canyon topography using finite-difference method. Journal of Applied Geophysics 159, 350-361. doi: 10.1016/j.jappgeo.2018.09.007.

Nolan M and Echelmeyer K (1999) Seismic detection of transient changes beneath Black Rapids Glacier, Alaska, V.S.A.: II. Basal morphology and processes. Journal of Glaciology 45(149), 132-146. doi: 10.3189/ S0022143000003117.

Nye JF (1976) Water flow in glaciers: jökulhlaups, tunnels and veins. Journal of Glaciology 17(76), 181-207. doi: 10.3189/S002214300001354X.

Olefs $\mathbf{M}$ and Lehning M. (2010) Textile protection of snow and ice: measured and simulated effects on the energy and mass balance. Cold Regions Science and Technology 62(2-3), 126-141. doi: 10.1016/j.coldregions.2010.03.0119.

Planes T and 5 others (2015) Time-lapse monitoring of internal erosion in earthen dams and levees using ambient seismic noise. Geotechnique 66 (4), 1-12, doi: 10.1680/jgeot.14.P.268.

Podolskiy EA and Walter F (2016) Cryoseismology. Reviews of Geophysics 54 (4), 708-758, doi: 10.1002/2016RG000526.

Pomeroy J, Brisbourne A, Evans J and Graham D (2013) The search for seismic signatures of movement at the glacier bed in a polythermal valley glacier. Annals of Glaciology 54(64), 149-156. doi: 10.3189/2013AoG64A203.

Preiswerk LE and Walter F (2018) High-frequency $(>2 \mathrm{~Hz})$ ambient seismic noise on high-melt glaciers: Green's function estimation and source characterization. Journal of Geophysical Research: Earth Surface 123(8), 16671681. doi: 10.1029/2017JF004498.

Roberts MJ (2005) Jökulhlaups: a reassessment of floodwater flow through glaciers. Reviews of Geophysics 43, RG1002. doi: 10.1029/2003RG000147.

Roberts MJ, Russell AJ, Tweed FS and Knudsen Ó (2000) Ice fracturing during jökulhlaups: implications for floodwater routing and outlet development. Earth Surface Processes and Landforms 25(13), 1429-1446.

Röthlisberger H (1972) Water pressure in intra- and subglacial channels. Journal of Glaciology 11(62), 177-203. doi: 10.3189/S0022143000022188.

Roux P, Sabra KG, Gerstoft P, Kuperman WA and Fehler MC (2005) P-waves from cross correlation of seismic noise. Geophysical Research Letters 32(19), L19303. doi: 10.1029/2005GL023803.

Sambridge M (1999) Geophysical inversion with a neighborhood algorithm. I: searching a parameter space. Geophysical Journal International 138(2), 479494. doi: 10.1046/j.1365-246X.1999.00876.x.

Schoof C (2010) Ice-sheet acceleration driven by melt supply variability. Nature 468(7325), 803-806. doi: 10.1038/nature09618.

Schulson EM and Duval P (2009) Creep and Fracture of Ice. Cambridge: Cambridge University Press. 
Schuster GT (2009) Seismic Interferometry. Cambridge: Cambridge University Press.

Schwab FA and Knopoff L (1972) Fast surface wave and free mode computations. In Bolt BA (ed.), Methods in Computational Physics. New York, Academic Press, pp. 87-180.

Sens-Schönfelder C and Wegler U (2006) Passive image interferometry and seasonal variations of seismic velocities at Merapi Volcano, Indonesia. Geophysical Research Letters 33(21), L21302. doi: 10.1029/2006GL027797.

Smith EC and 7 others (2017) Ice fabric in an Antarctic ice stream interpreted from seismic anisotropy. Geophysical Research Letters 44(8), 3710-3718. doi: 10.1002/2016GL072093.

Snieder R (2004) Extracting the Green's function from the correlation of coda waves: a derivation based on stationary phase. Physical Review E 69, 046610. doi: 10.1103/PhysRevE.69.046610.

Snieder R (2006) The theory of coda wave interferometry. Pure and Applied Geophysics 163, 455-473. doi: 10.1007/s00024-005-0026-6.

Snieder R, Wapenaar K and Larner K (2006) Spurious multiples in seismic interferometry of primaries. Geophysics 71(4), SI111-SI124. doi: 10.1190/ 1.2211507.

Snorrason Á and 7 others (1997) Hlaupið Á Skeiðarársandi Haustið 1996: Útbreiðsla, rennsli og aurburður. In Haraldsson H (ed.), Vatnajökull: Gos og hlaup 1996. Reykjavík: Vegagerðin, pp. 79-137.

Søndergaard J and 7 others (2015) Mercury exports from a High-Arctic river basin in Northeast Greenland $\left(74^{\circ} \mathrm{N}\right)$ largely controlled by glacial lake outburst floods. Science of the Total Environment 514, 83-91. doi: 10. 1016/j.scitotenv.2015.01.097.

Spring U and Hutter K (1981) Numerical studies of Jökulhlaups. Cold Regions Science and Technology 4(3), 227-244. doi: 10.1016/0165-232X(81)90006-9.

Spring U and Hutter K (1982) Conduit flow of a fluid through its solid phase and its application to intraglacial channel flow. International Journal of Engineering Science 20(2), 327-363. doi: 10.1016/0020-7225(82)90029-5.

Stein S and Wyssesion M (2003) An Introduction to Seismology, Earthquakes, and Earth Structure. Malden, Oxford, Victoria: Blackwell Publishing.

Stich D and Morelli A (2007) Reflection of seismic surface waves at the northern Apennines. Earth and Planetary Science Letters 259(2), 149-158. doi.org/10.1016/j.epsl.2007.04.036.

Terzaghi K (1936) The shearing resistance of saturated soils and the angle between the planes of shear. Proceedings of the First International Conference of Soil Mechanics and Foundation Engineering, Harvard University, Vol. 1, pp. 54-56.

Tsai VC (2009) On establishing the accuracy of noise tomography traveltime measurements in a realistic medium. Geophysical Journal International 178 (3), 1555-1564. doi: 10.1111/j.1365-246X.2009.04239.x.

Tsai VC and Rice JR (2010) A model for turbulent hydraulic fracture and application to crack propagation at glacier beds. Journal of Geophysical Research: Earth Surface 115(F3), F03007. doi:10.1029/2009JF001474.

Tsuji T, Johansen TA, Ruud BO, Ikeda T and Matsuoka T (2012) Surface-wave analysis for identifying unfrozen zones in subglacial sediments. Geophysics 77(3), EN17-EN27. doi: 10.1190/GEO2011-0222.1.

Tweed FS and Russell AJ (1999) Controls on the formation and sudden drainage of glacier-impounded lakes: implications for jökulhlaup characteristics. Progress in Physical Geography 23(1), 79-110. doi: 10.1177/ 030913339902300104.

van der Veen C (2007) Fracture propagation as means of rapidly transferring meltwater to the base of glaciers. Geophysical Research Letters 34(1), L01501. doi: 10.1029/2006GL028385.

VanWormer D and Berg E (1973) Seismic evidence for glacier movement. Journal of Glaciology 12(65), 259-265. doi: 10.3189/S002214300003207X.

Vélez JA, Tsoflias GP, Black RA, van der Veen CJ and Anandakrishnan S (2016). Distribution of preferred ice crystal orientation determined from seismic anisotropy: evidence from Jakobshavn Isbræ and the North Greenland Eemian Ice Drilling facility, Greenland. Geophysics 81(1), WA111-WA1118. doi: 10.1190/geo2015-0154.1.

Vidale JE (1986) Complex polarization analysis of particle motion. Bulletin of the Seismological Society of America 76(5), 1393-1405.

Vore ME, Bartholomaus TC, Winberry JP, Walter JI and Amundson JM (2019) Seismic tremor reveals spatial organization and temporal changes of subglacial water system. Journal of Geophysical Research: Earth Surface 124(2), 427-446. doi: 10.1029/2018JF004819.

Walter F and 5 others (2009) Moment tensor inversions of icequakes on Gornergletscher, Switzerland. Bulletin of the Seismological Society of America 99(2A), 852-870. doi: 10.1785/0120080110.

Walter F and 5 others (2015) Using glacier seismicity for phase velocity measurements and Green's function retrieval. Geophysical Journal International 201(3), 1722-1737. doi: 10.1093/gji/ggv069.

Walter F, Chaput J and Lüthi MP (2014) Thick sediments beneath Greenland's ablation zone and their potential role in future ice sheet dynamics. Geology 42(6), 487-490. doi: 10.1130/G35492.1.

Walter F, Clinton JF, Dreger DS, Deichmann N and Funk M (2010) Evidence for near-horizontal tensile faulting at the base of Gornergletscher, a Swiss alpine glacier. Bulletin of the Seismological Society of America 100(2), 458472. doi: 10.1785/0120090083.

Walter F, Deichmann N and Funk M (2008) Basal icequakes during changing subglacial water pressures beneath Gornergletscher, Switzerland. Journal of Glaciology 54(186), 511-521. doi: 10.3189/002214308785837110.

Wapenaar K, Draganov D, Snieder R, Campman X and Verdel A (2010a) Tutorial on seismic interferometry: Part 1 - basic principles and applications. Geophysics 75(5), 75A195-75A209. doi: 10.1190/1.3457445.

Wapenaar K, Slob E, Snieder R and Curtis A (2010b) Tutorial on seismic interferometry: Part 2 - underlying theory and advances. Geophysics $\mathbf{7 5}$ (5), 75A211-75A227. doi: 10.1190/1.3463440.

Wathelet M (2008). An improved neighborhood algorithm: parameter conditions and dynamic scaling. Geophysical Research Letters 35(9), L09301. doi: 10.1029/2008GL033256.

Wathelet M, Jongmans D and Ohrnberger M (2004) Surface wave inversion using a direct search algorithm and its application to ambient vibration measurements. Near Surface Geophysics 2(4), 211-221. doi: 10.3997/ 1873-0604.2004018.

Weaver CS and Malone SD (1979) Seismic evidence for discrete glacier motion at the rock-ice interface. Journal of Glaciology 23(89), 171-184. doi: $10.1017 /$ S0022143000029816.

Weidick A and Citterio M (2011) The ice-dammed lake Isvand, West Greenland, has lost its water. Journal of Glaciology 57(201), 186-188. doi: 10.3189/002214311795306600.

West ME, Larsen C, Truffer M, O'Neel S and LeBlanc L (2010) Glacier microseismicity. Geology 38(4), 319-322. doi: 10.1130/G30606.1.

Xia J, Miller RD and Park CB (1999) Estimation of near-surface shearwave velocity by inversion of Rayleigh wave. Geophysics 64(3), 691-700. doi: 10.1190/1.1444578.

Yao H, van der Hilst RD and de Hoop MV (2006) Surface-wave array tomography in SE Tibet from ambient seismic noise and two-station analysis I. Phase velocity maps. Geophysical Journal International 166(2), 732-744. doi: 10.1111/j.1365-246X.2006.03028.x.

Yao H, Xu G, Zhu L and Xiao X (2005) Mantle structure from inter-station Rayleigh wave dispersion and its tectonic implication in western China and neighbouring regions. Physics of the Earth and Planetary Interiors 148(1), 39-54. doi: 10.1016/j.pepi.2004.08.006.

Zhan Z (2019) Seismic noise interferometry reveals transverse drainage configuration beneath the surging Bering Glacier. Geophysical Research Letters 46 (9), 4747-4756. 